\title{
Multiple Bi(III)-thioether Secondary Interactions Integrate Metalloporphyrin Ligands into Functional Networks
}

\author{
Kunhao Li ${ }^{\mathrm{a}}$, Guo Huang ${ }^{\mathrm{b}}$, Zhengtao Xu* ${ }^{* \mathrm{~b}}$, Mingliang Zhang ${ }^{\mathrm{b}}$, Matthias Zeller ${ }^{\mathrm{c}}$, Allen D. \\ Hunter $^{\mathrm{c}}$, Stephen Sin-Yin Chui ${ }^{\mathrm{d}}$, Chi-Ming Che ${ }^{\mathrm{d}}$, Wai-Yeung Wong ${ }^{\mathrm{e}}$ \\ ${ }^{a}$ Department of Chemistry, the George Washington University, 725 21st Street NW, \\ Washington, DC 20052. \\ ${ }^{\mathrm{b}}$ Department of Biology and Chemistry, City University of Hong Kong, 83 Tat Chee Avenue, \\ Kowloon, Hong Kong, China. \\ ${ }^{c}$ Department of Chemistry, Youngstown State University, One University Plaza, Youngstown, \\ Ohio 44555. \\ d Department of Chemistry, The University of Hong Kong, Pokfulam Road, Hong Kong, China. \\ ${ }^{\mathrm{e}}$ Department of Chemistry, Hong Kong Baptist University, Waterloo Road, Kowloon Tong, \\ Hong Kong, China.
}

* Corresponding author; Fax: $852 \quad 2788$ 7406; Tel: 8522784 4679; E-mail: zhengtao@cityu.edu.hk

Supporting Information 


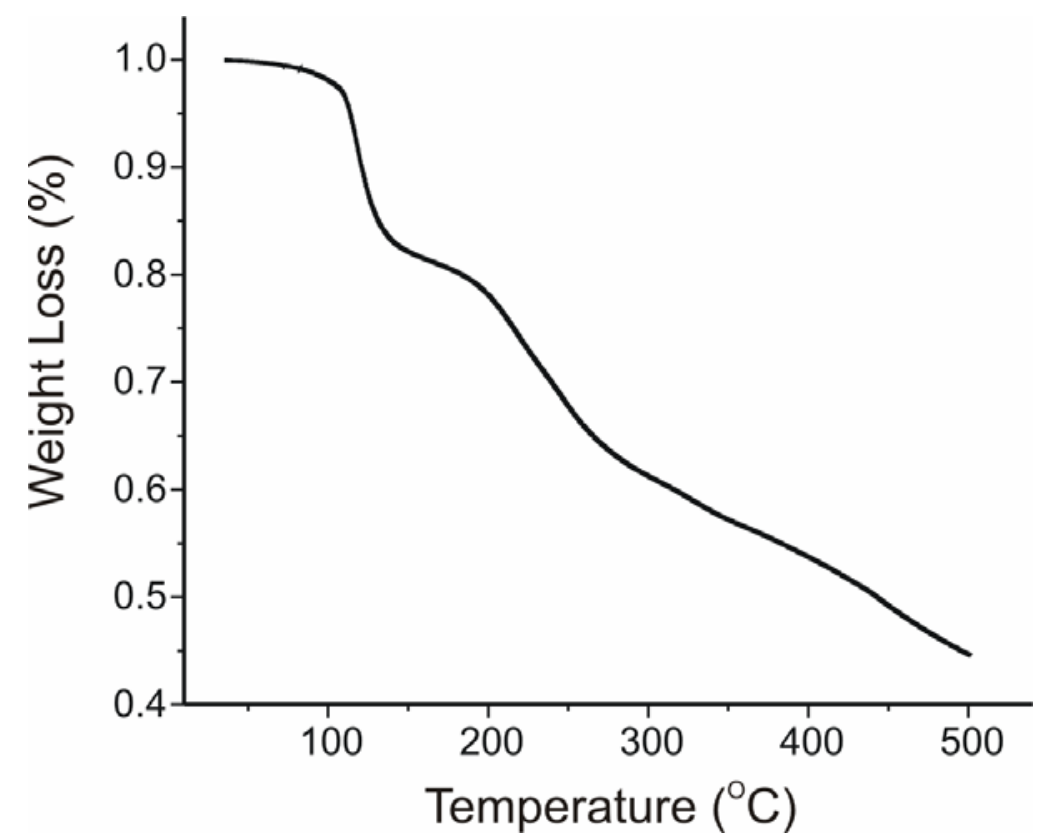

Figure S1. Thermogram for a solid sample of $\mathbf{2}$ in a nitrogen atmosphere.

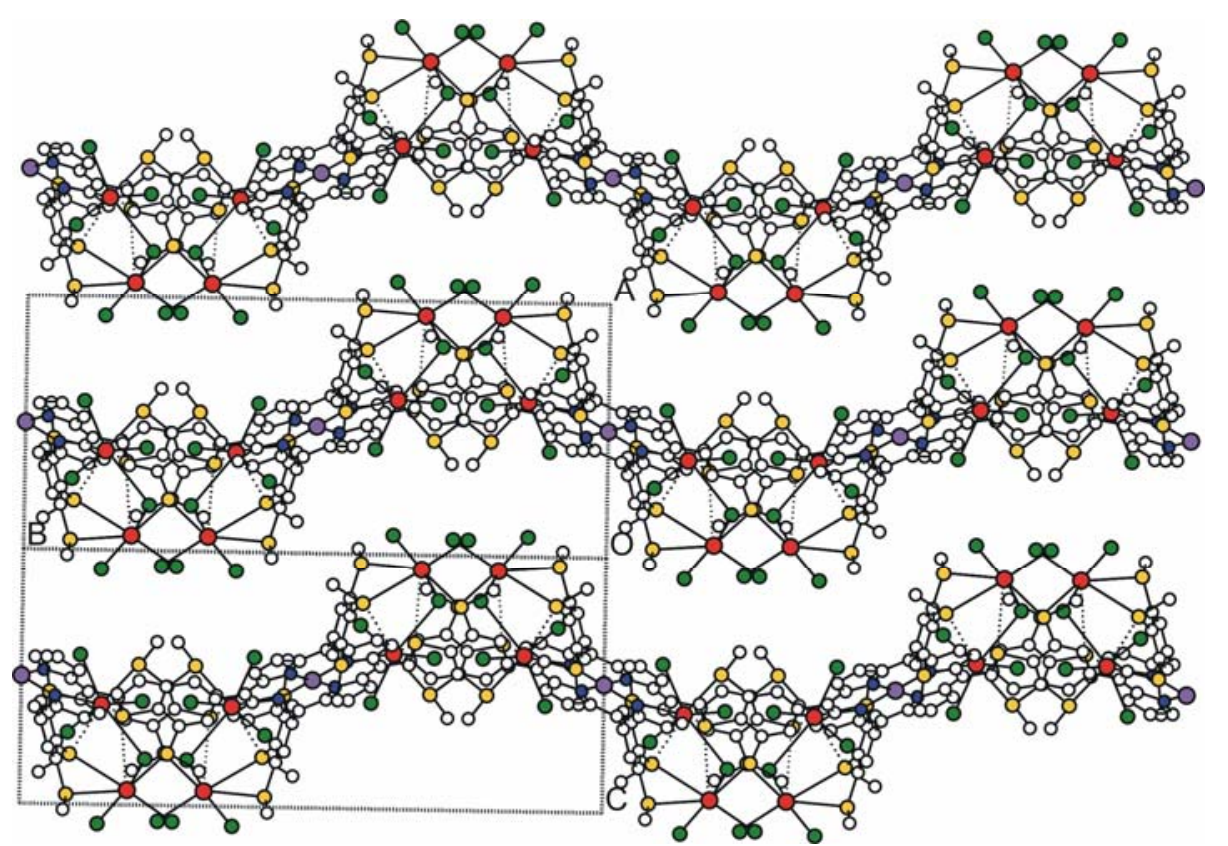

Figure S2. View of the 2D layers in 2 (along [ $\left[\begin{array}{lll}-1 & 0 & 1\end{array}\right]$ direction, parallel to the layers). The guest molecules are removed. Large red sphere: $\mathrm{Bi}$; large purple: $\mathrm{Zn}$; medium green: Br; medium orange: S; small white: $\mathrm{C}$; small blue: $\mathrm{N}$. 


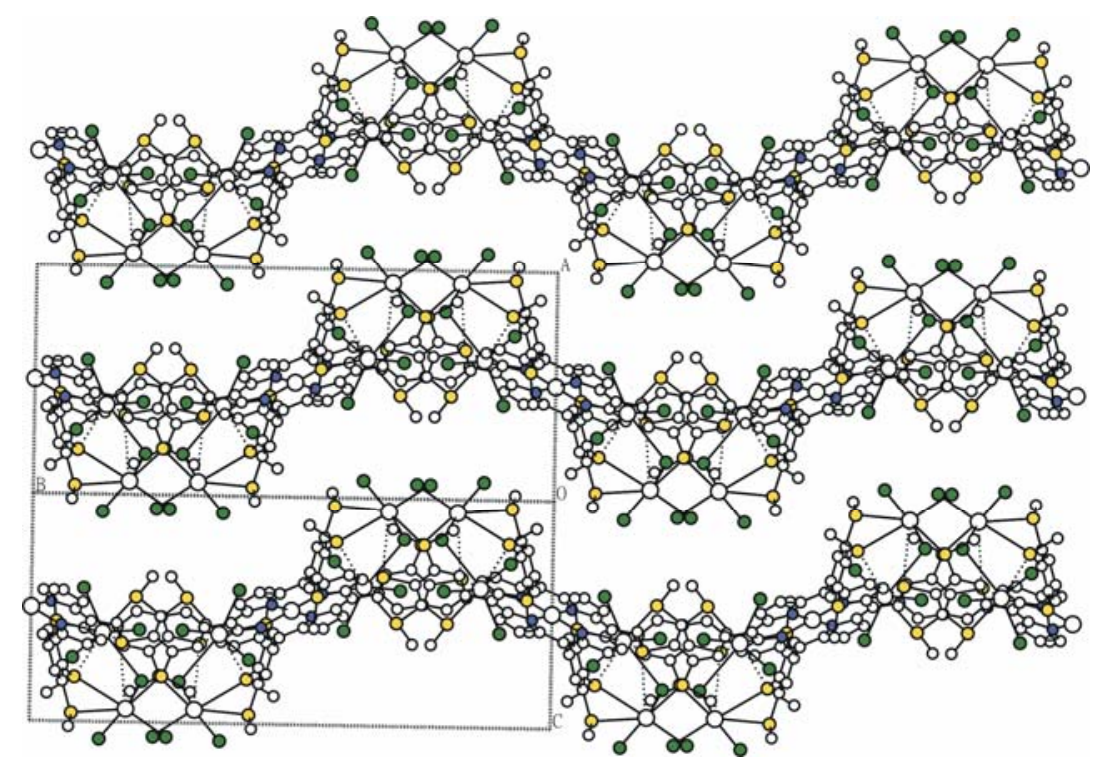

Figure S3. View of the 2D layers in 2 (along [ $\left[\begin{array}{lll}-1 & 0 & 1\end{array}\right]$ direction, parallel to the layers). The guest molecules are removed. Large white sphere: $\mathrm{Bi}$ or $\mathrm{Zn}$; medium green: Br; medium orange: S; small white: $\mathrm{C}$; small blue: $\mathrm{N}$.

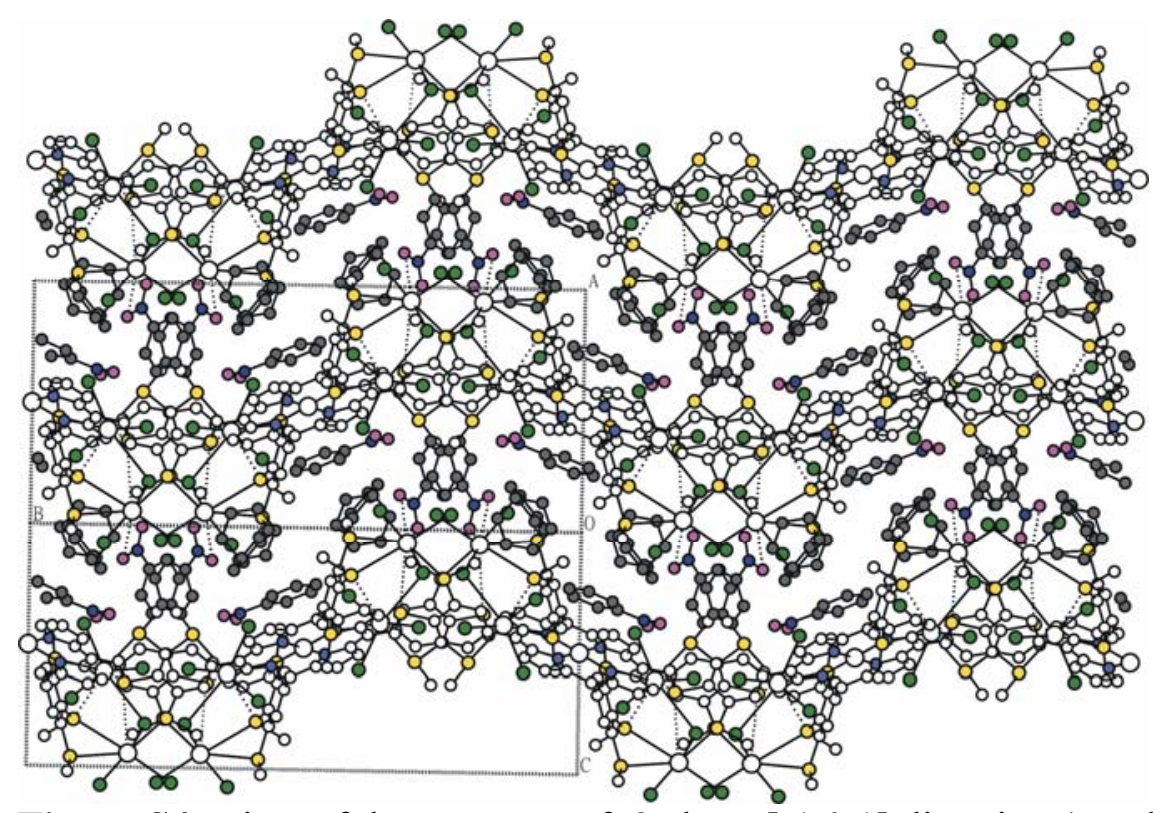

Figure S4. View of the structure of 2 along [ $\left[\begin{array}{lll}-1 & 0 & 1\end{array}\right]$ direction (parallel to the layers), with the benzene and nitrobenzene molecules. Large white sphere: $\mathrm{Bi}$ or $\mathrm{Zn}$; medium green: Br; medium orange: $\mathrm{S}$; small blue: $\mathrm{N}$; pink, $\mathrm{O}$; small white: $\mathrm{C}$ atoms on the host net; small grey, $\mathrm{C}$ atoms on the benzene and nitrobenzene guests. 
MSPORZn - Expt (blue) \& Calc (red) PXRD patterns

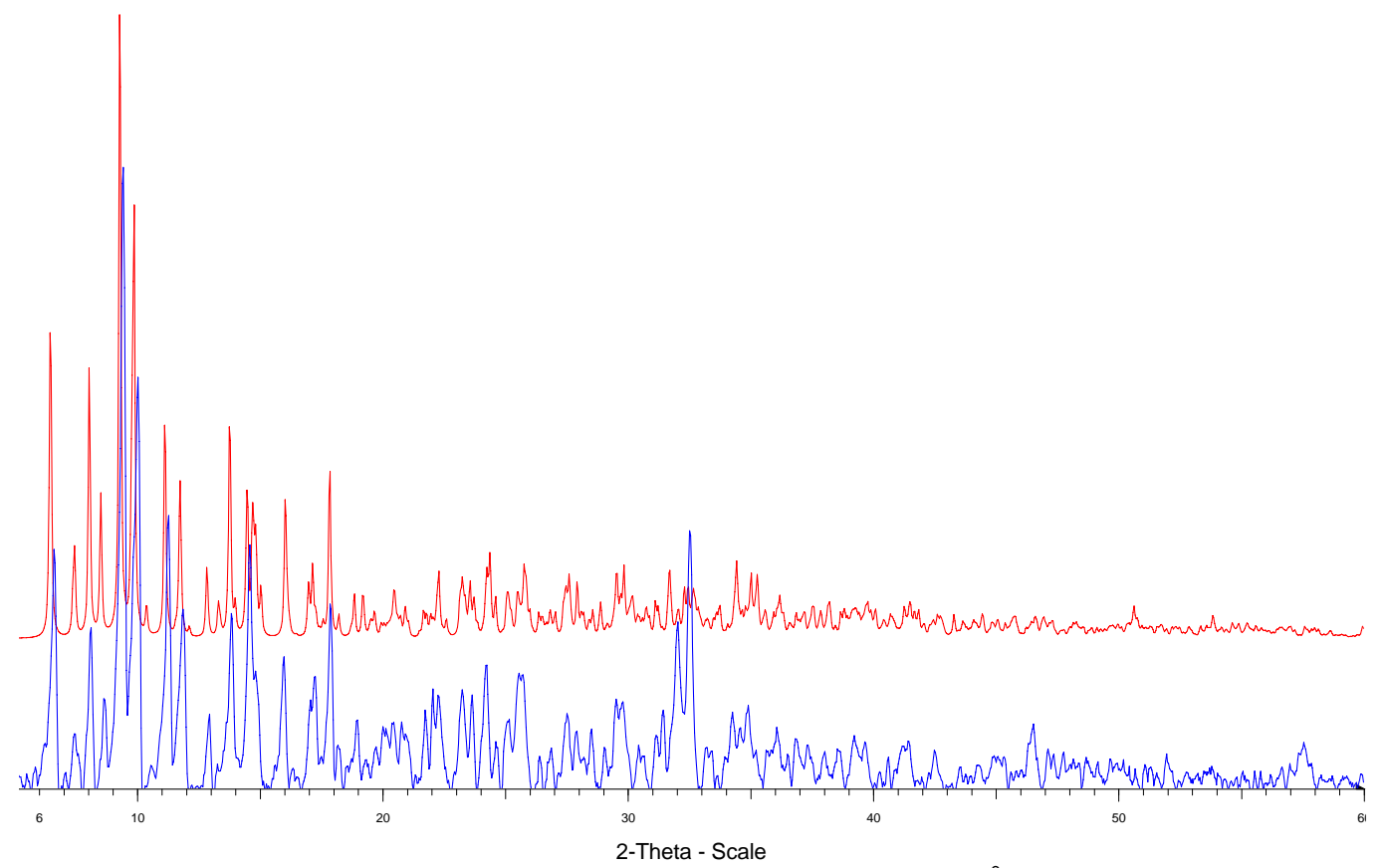

Figure S5. X-ray diffraction patterns $(\mathrm{Cu} \mathrm{K} \alpha, \lambda=1.5418 \AA)$ for a powder sample of 2. Top (red): calculated from the single crystal structure of 2 (single crystal data collected at $100 \mathrm{~K}$ ). Top: observed pattern at $298 \mathrm{~K}$. 


\section{Further Crystallographic Data from X-ray Single Crystal Diffraction Studies}

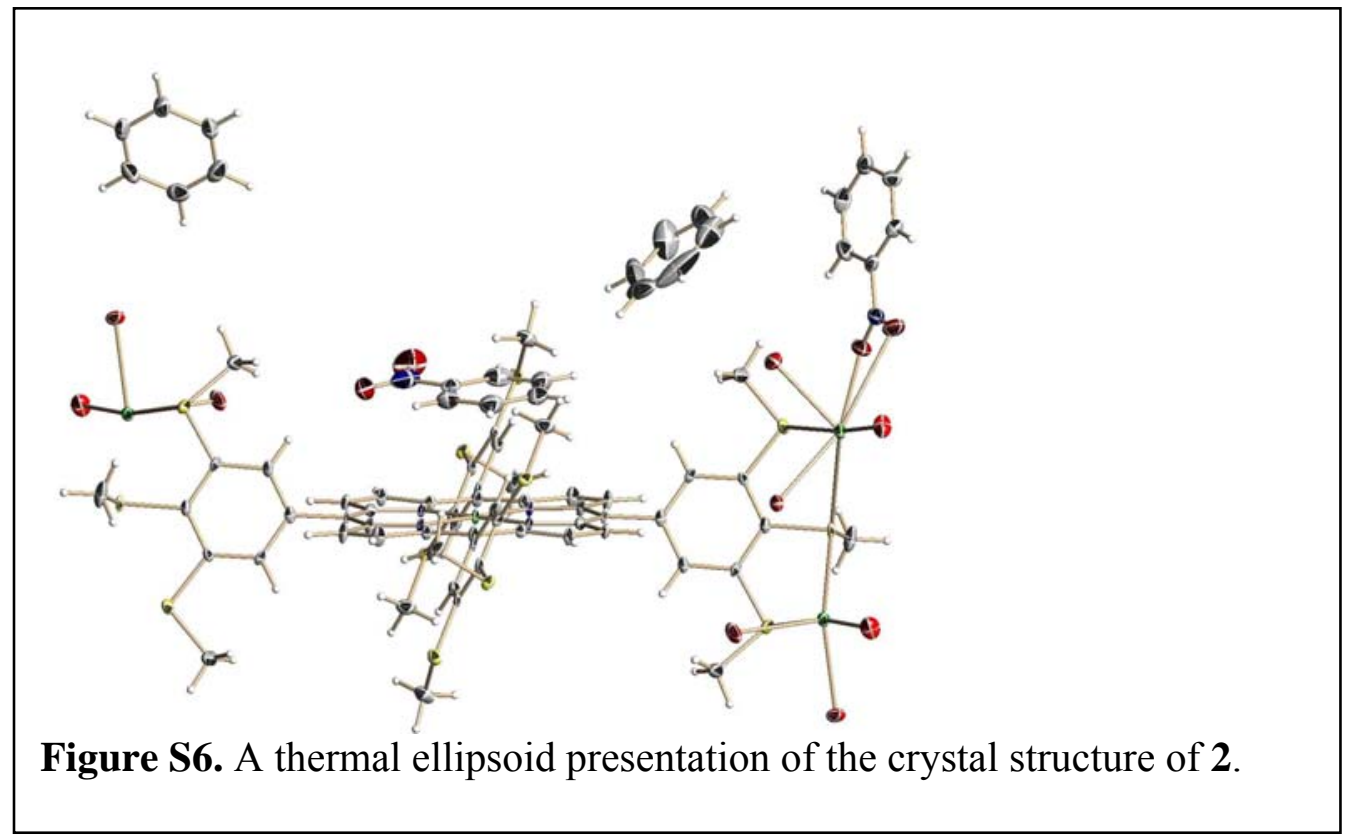

Table s1. Crystal data and structure refinement for 2:

Identification code: $05 \mathrm{mz} 058 \mathrm{~m}$

Empirical formula: C104 H96 Bi4 Br12 N8 08 S12 Zn

Moiety formula: C56 H52 N4 S12 Zn, 4(C6 H5 N 02), 4(C6 H6), 4(Bi Br3)

Formula weight: 3830.84

Temperature: $100(2) \mathrm{K}$

Wavelength: $0.71073 \AA$

Crystal system: Monoclinic

Space group: $\mathrm{P} 2{ }_{1} / \mathrm{n}$

Unit cell dimensions:

$a=13.894(2) \AA, \alpha=90^{\circ}$

$\mathrm{b}=27.684(5) \AA, \beta=106.879(3)^{\circ}$

$c=16.744(3) \AA, \gamma=90^{\circ}$

Volume, $Z: 6162.9(18) \AA^{3}, 2$

Density (calculated): $2.064 \mathrm{Mg} / \mathrm{m}^{3}$ 
Absorption coefficient: $10.032 \mathrm{~mm}^{-1}$

$F(\odot \odot 0)$ : 3628

Crystal size: $0.32 \times 0.25 \times 0.1 \mathrm{~mm}$

Crystal shape, color: plate, red

$\theta$ range for data collection: 1.47 to $28.28^{\circ}$

Limiting indices: $-18 \leq h \leq 18,-36 \leq k \leq 36,-22 \leq 1 \leq 22$

Reflections collected: 63259

Independent reflections: $15310(R$ (int $)=0.0601)$

Completeness to $\theta=28.28^{\circ}: 100.0 \%$

Absorption correction: multi-scan

Max. and min. transmission: 0.37 and 0.0708

Refinement method: Full-matrix least-squares on $F^{2}$

Data / restraints / parameters: 15310 / $\odot$ / 679

Goodness-of-fit on $F^{2}: 1.056$

Final $R$ indices $[I>2 \sigma(I)]: \mathrm{R} 1=0.0310, \mathrm{WR} 2=0.0756$

$R$ indices (all data): R1 $=0.0372$, WR2 $=0.0780$

Largest diff. peak and hole: 2.507 and $-1.029 \mathrm{e} \times \AA^{-3}$

Refinement of $\mathrm{F}^{2}$ against ALL reflections. The weighted $\mathrm{R}$-factor $\mathrm{WR}$ and goodness of fit are based on $\mathrm{F}^{2}$, conventional $\mathrm{R}$-factors $\mathrm{R}$ are based on $F$, with $F$ set to zero for negative $F^{2}$. The threshold expression of $\mathrm{F}^{2}>2 \sigma\left(\mathrm{F}^{2}\right)$ is used only for calculating R-factors.

Treatment of hydrogen atoms:

All hydrogen atoms were placed in calculated positions and were refined with an isotropic displacement parameter 1.2 times that of the adjacent carbon atom.

Table S2. Atomic coordinates $\left[\times 10^{4}\right]$ and equivalent isotropic displacement parameters $\left[\AA^{2} \times 10^{3}\right]$ for 2 . $U(e q)$ is defined as one third of the trace of the orthogonalized $U_{i j}$ tensor.

\begin{tabular}{|c|c|c|c|c|}
\hline & $x$ & $\mathrm{y}$ & $z$ & $\mathrm{U}(\mathrm{eq})$ \\
\hline $\mathrm{Bi}(1)$ & $6339(1)$ & $1382(1)$ & $10248(1)$ & $16(1)$ \\
\hline $\mathrm{Bi}(2)$ & $6929(1)$ & $1842(1)$ & $7505(1)$ & $17(1)$ \\
\hline $\operatorname{Br}(1)$ & $7944(1)$ & $805(1)$ & $10752(1)$ & $30(1)$ \\
\hline $\operatorname{Br}(2)$ & $5448(1)$ & $1005(1)$ & $11306(1)$ & $25(1)$ \\
\hline $\mathrm{Br}(3)$ & $7221(1)$ & $2084(1)$ & $11272(1)$ & $30(1)$ \\
\hline $\operatorname{Br}(4)$ & $7721(1)$ & $2630(1)$ & $7094(1)$ & $33(1)$ \\
\hline $\mathrm{Br}(5)$ & $7295(1)$ & $2138(1)$ & $9088(1)$ & $22(1)$ \\
\hline $\operatorname{Br}(6)$ & $8626(1)$ & $1343(1)$ & $7863(1)$ & $30(1)$ \\
\hline $\mathrm{C}(1)$ & $2976(3)$ & $4769(1)$ & $8726(2)$ & $14(1)$ \\
\hline$C(2)$ & $2439(3)$ & $4386(1)$ & $8199(2)$ & $19(1)$ \\
\hline
\end{tabular}




\begin{tabular}{|c|c|c|c|c|}
\hline$C(3)$ & $3071(3)$ & $4006(1)$ & $8304(2)$ & $18(1)$ \\
\hline$C(4)$ & $3994(3)$ & $4147(1)$ & $8918(2)$ & $14(1)$ \\
\hline$C(5)$ & $4830(3)$ & $3845(1)$ & $9238(2)$ & $14(1)$ \\
\hline$C(6)$ & $5722(3)$ & $3970(1)$ & $9823(2)$ & $14(1)$ \\
\hline$C(7)$ & $6565(3)$ & $3650(1)$ & $10140(2)$ & $16(1)$ \\
\hline$C(8)$ & $7295(3)$ & $3906(1)$ & $10690(2)$ & $16(1)$ \\
\hline$C(9)$ & $6911(3)$ & $4390(1)$ & $10710(2)$ & $13(1)$ \\
\hline$C(10)$ & $7423(3)$ & $4768(1)$ & $11220(2)$ & $14(1)$ \\
\hline$C(11)$ & $4749(2)$ & $3331(1)$ & $8947(2)$ & $13(1)$ \\
\hline$C(12)$ & $4652(2)$ & $2975(1)$ & $9505(2)$ & $14(1)$ \\
\hline$C(13)$ & $4619(3)$ & $2487(1)$ & $9277(2)$ & $14(1)$ \\
\hline$C(14)$ & $4709(3)$ & $2363(1)$ & $8487(2)$ & $15(1)$ \\
\hline$C(15)$ & $4801(3)$ & $2722(1)$ & $7924(2)$ & $15(1)$ \\
\hline$C(16)$ & $4811(3)$ & $3206(1)$ & $8161(2)$ & $15(1)$ \\
\hline$C(17)$ & $4492(4)$ & $2321(2)$ & $10886(3)$ & $29(1)$ \\
\hline$C(18)$ & $3405(3)$ & $1646(1)$ & $7738(3)$ & $31(1)$ \\
\hline$C(19)$ & $5098(4)$ & $3079(2)$ & $6455(3)$ & $34(1)$ \\
\hline$C(20)$ & $8457(3)$ & $4659(1)$ & $11758(2)$ & $13(1)$ \\
\hline$C(21)$ & $8645(3)$ & $4663(1)$ & $12627(2)$ & $14(1)$ \\
\hline$C(22)$ & $9580(3)$ & $4523(1)$ & $13150(2)$ & $14(1)$ \\
\hline$C(23)$ & $10339(2)$ & $4383(1)$ & $12798(2)$ & $13(1)$ \\
\hline$C(24)$ & $10156(3)$ & $4386(1)$ & $11927(2)$ & $14(1)$ \\
\hline$C(25)$ & $9217(3)$ & $4525(1)$ & $11416(2)$ & $16(1)$ \\
\hline$C(26)$ & $8639(3)$ & $4568(2)$ & $14404(3)$ & $26(1)$ \\
\hline$C(27)$ & $12313(3)$ & $4680(1)$ & $13552(3)$ & $27(1)$ \\
\hline$C(28)$ & $10653(3)$ & $4253(2)$ & $10435(2)$ & $25(1)$ \\
\hline$C(29)$ & $4907(3)$ & $5682(2)$ & $8096(3)$ & $31(1)$ \\
\hline$C(30)$ & $5803(4)$ & $5591(2)$ & $8667(3)$ & $36(1)$ \\
\hline$C(31)$ & $6236(4)$ & $5153(2)$ & $8678(3)$ & $37(1)$ \\
\hline$C(32)$ & $5765(4)$ & $4802(2)$ & $8114(3)$ & $33(1)$ \\
\hline$C(33)$ & $4857(3)$ & $4880(2)$ & $7529(3)$ & $34(1)$ \\
\hline$C(34)$ & $4399(4)$ & $5326(2)$ & $7500(3)$ & $42(1)$ \\
\hline$C(35)$ & $6409(3)$ & $2176(1)$ & $4571(2)$ & $22(1)$ \\
\hline$C(36)$ & $7120(3)$ & $2035(1)$ & $4187(2)$ & $22(1)$ \\
\hline$C(37)$ & $7090(3)$ & $2239(2)$ & $3429(3)$ & $26(1)$ \\
\hline$C(38)$ & $6369(3)$ & $2583(1)$ & $3073(3)$ & $27(1)$ \\
\hline$C(39)$ & $5669(4)$ & $2716(2)$ & $3463(3)$ & $35(1)$ \\
\hline$C(40)$ & $5682(3)$ & $2518(2)$ & $4227(3)$ & $33(1)$ \\
\hline $\mathrm{N}(4)$ & $6431(3)$ & $1953(1)$ & $5364(2)$ & $28(1)$ \\
\hline$O(3)$ & $5726(3)$ & $2030(1)$ & $5652(2)$ & $39(1)$ \\
\hline O (4) & $7154(3)$ & $1697(1)$ & $5723(2)$ & $37(1)$ \\
\hline$C(41)$ & $6171(5)$ & $3877(2)$ & $4688(4)$ & $58(2)$ \\
\hline$C(42)$ & $5598(5)$ & $4191(3)$ & $4984(5)$ & $72(2)$ \\
\hline$C(43)$ & $5909(7)$ & $4319(3)$ & $5799(6)$ & $84(3)$ \\
\hline$C(44)$ & $6757(8)$ & $4154(3)$ & $6314(4)$ & $85(3)$ \\
\hline$C(45)$ & $7347(6)$ & $3844(3)$ & $6018(6)$ & $93(3)$ \\
\hline$C(46)$ & $7034(5)$ & $3707(2)$ & $5196(5)$ & $65(2)$ \\
\hline$C(47)$ & $5901(4)$ & $8477(2)$ & $6429(3)$ & $35(1)$ \\
\hline$C(48)$ & $6635(3)$ & $8636(2)$ & $6092(3)$ & $31(1)$ \\
\hline$C(49)$ & $6854(3)$ & $9127(2)$ & $6106(3)$ & $29(1)$ \\
\hline$C(50)$ & $6327(4)$ & $9449(2)$ & $6459(3)$ & $32(1)$ \\
\hline$C(51)$ & $5597(4)$ & $9284(2)$ & $6789(3)$ & $35(1)$ \\
\hline$C(52)$ & $5375(4)$ & $8795(2)$ & $6763(3)$ & $37(1)$ \\
\hline $\mathrm{N}(1)$ & $3917(2)$ & $4618(1)$ & $9162(2)$ & $13(1)$ \\
\hline$N(2)$ & $5946(2)$ & $4419(1)$ & $10184(2)$ & $13(1)$ \\
\hline$N(3)$ & $4438(4)$ & $6162(2)$ & $8057(3)$ & $50(1)$ \\
\hline$O(1)$ & $4845(4)$ & $6462(1)$ & $8566(3)$ & $58(1)$ \\
\hline$O(2)$ & $3648(4)$ & $6232(2)$ & $7491(3)$ & $72(1)$ \\
\hline$S(1)$ & $4435(1)$ & $2014(1)$ & $9921(1)$ & $18(1)$ \\
\hline$S(2)$ & $4733(1)$ & $1745(1)$ & $8214(1)$ & $17(1)$ \\
\hline$S(3)$ & $4928(1)$ & $2524(1)$ & $6961(1)$ & $20(1)$ \\
\hline
\end{tabular}




$\begin{array}{lrlll}\text { S (4) } & 9858(1) & 4511(1) & 14248(1) & 17(1) \\ \text { S (5) } & 11496(1) & 4158(1) & 13448(1) & 15(1) \\ \text { S (6) } & 11163(1) & 4207(1) & 11549(1) & 17(1) \\ \text { Zn (1) } & 5000 & 5000 & 10000 & 12(1)\end{array}$

All esds (except the esd in the dihedral angle between two 1.s. planes) are estimated using the full covariance matrix. The cell esds are taken into account individually in the estimation of esds in distances, angles and torsion angles; correlations between esds in cell parameters are only used when they are defined by crystal symmetry. An approximate (isotropic) treatment of cell esds is used for estimating esds involving l.s. planes.

Table S3. Bond lengths $[\AA]$ and angles [deg] for 2.

\begin{tabular}{|c|c|c|c|}
\hline $\mathrm{Zn}(1)-\mathrm{C}(31)$ & $3.1995(48)$ & $C(13)-C(14)$ & $1.406(5)$ \\
\hline $\operatorname{Zn}(1)-\mathrm{C}(30)$ & $3.2160(45)$ & $C(13)-S(1)$ & $1.762(3)$ \\
\hline $\mathrm{Bi}(2)-\mathrm{S}(6) \# 2$ & $3.3372(10)$ & $C(14)-C(15)$ & $1.402(5)$ \\
\hline $\mathrm{Bi}(2)-\mathrm{S}(5) \# 2$ & $3.3260(10)$ & $C(14)-S(2)$ & $1.772(3)$ \\
\hline $\mathrm{Bi}(1)-\mathrm{S}(5) \# 2$ & $3.4275(10)$ & $C(15)-C(16)$ & $1.397(4)$ \\
\hline $\mathrm{Bi}(1)-\mathrm{S}(4) \# 2$ & $3.3394(9)$ & $C(15)-S(3)$ & $1.759(4)$ \\
\hline $\mathrm{Bi}(2)-\mathrm{O}(4)$ & $3.1157(32)$ & $\mathrm{C}(16)-\mathrm{H}(16)$ & 0.9500 \\
\hline $\mathrm{Bi}(2)-\mathrm{O}(3)$ & $3.1115(36)$ & $C(17)-S(1)$ & $1.805(4)$ \\
\hline $\mathrm{Bi}(2)-\mathrm{S}(2)$ & $3.5900(11)$ & $\mathrm{C}(17)-\mathrm{H}(17 \mathrm{~A})$ & 0.9800 \\
\hline $\mathrm{Bi}(2)-\mathrm{S}(3)$ & $3.2643(10)$ & $\mathrm{C}(17)-\mathrm{H}(17 \mathrm{~B})$ & 0.9800 \\
\hline $\mathrm{Bi}(1)-\mathrm{Br}(3)$ & $2.6449(5)$ & $\mathrm{C}(17)-\mathrm{H}(17 \mathrm{C})$ & 0.9800 \\
\hline $\mathrm{Bi}(1)-\mathrm{Br}(2)$ & $2.6519(5)$ & $C(18)-S(2)$ & $1.806(4)$ \\
\hline $\mathrm{Bi}(1)-\mathrm{Br}(1)$ & $2.6735(5)$ & $\mathrm{C}(18)-\mathrm{H}(18 \mathrm{~A})$ & 0.9800 \\
\hline $\mathrm{Bi}(1)-\mathrm{S}(1)$ & $3.0851(10)$ & $\mathrm{C}(18)-\mathrm{H}(18 \mathrm{~B})$ & 0.9800 \\
\hline $\mathrm{Bi}(1)-\mathrm{S}(2)$ & $3.6296(10)$ & $\mathrm{C}(18)-\mathrm{H}(18 \mathrm{C})$ & 0.9800 \\
\hline $\mathrm{Bi}(2)-\mathrm{Br}(4)$ & $2.6243(5)$ & $C(19)-S(3)$ & $1.801(4)$ \\
\hline $\mathrm{Bi}(2)-\mathrm{Br}(6)$ & $2.6457(6)$ & $\mathrm{C}(19)-\mathrm{H}(19 \mathrm{~A})$ & 0.9800 \\
\hline $\mathrm{Bi}(2)-\mathrm{Br}(5)$ & $2.6785(6)$ & $\mathrm{C}(19)-\mathrm{H}(19 \mathrm{~B})$ & 0.9800 \\
\hline $\mathrm{C}(1)-\mathrm{N}(1)$ & $1.365(4)$ & $\mathrm{C}(19)-\mathrm{H}(19 \mathrm{C})$ & 0.9800 \\
\hline$C(1)-C(10) \# 1$ & $1.411(5)$ & $C(20)-C(25)$ & $1.389(5)$ \\
\hline$C(1)-C(2)$ & $1.442(5)$ & $C(20)-C(21)$ & $1.403(5)$ \\
\hline$C(2)-C(3)$ & $1.347(5)$ & $C(21)-C(22)$ & $1.395(5)$ \\
\hline $\mathrm{C}(2)-\mathrm{H}(2)$ & 0.9500 & $\mathrm{C}(21)-\mathrm{H}(21)$ & 0.9500 \\
\hline$C(3)-C(4)$ & $1.444(5)$ & $C(22)-C(23)$ & $1.403(5)$ \\
\hline $\mathrm{C}(3)-\mathrm{H}(3)$ & 0.9500 & $C(22)-S(4)$ & $1.765(4)$ \\
\hline $\mathrm{C}(4)-\mathrm{N}(1)$ & $1.381(4)$ & $C(23)-C(24)$ & $1.407(5)$ \\
\hline$C(4)-C(5)$ & $1.404(5)$ & $C(23)-S(5)$ & $1.772(3)$ \\
\hline$C(5)-C(6)$ & $1.382(5)$ & $C(24)-C(25)$ & $1.390(5)$ \\
\hline$C(5)-C(11)$ & $1.496(4)$ & $C(24)-S(6)$ & $1.766(4)$ \\
\hline$C(6)-N(2)$ & $1.378(4)$ & $\mathrm{C}(25)-\mathrm{H}(25)$ & 0.9500 \\
\hline$C(6)-C(7)$ & $1.441(5)$ & $C(26)-S(4)$ & $1.795(4)$ \\
\hline$C(7)-C(8)$ & $1.356(5)$ & $\mathrm{C}(26)-\mathrm{H}(26 \mathrm{~A})$ & 0.9800 \\
\hline $\mathrm{C}(7)-\mathrm{H}(7)$ & 0.9500 & $\mathrm{C}(26)-\mathrm{H}(26 \mathrm{~B})$ & 0.9800 \\
\hline$C(8)-C(9)$ & $1.447(4)$ & $\mathrm{C}(26)-\mathrm{H}(26 \mathrm{C})$ & 0.9800 \\
\hline $\mathrm{C}(8)-\mathrm{H}(8)$ & 0.9500 & $C(27)-S(5)$ & $1.814(4)$ \\
\hline $\mathrm{C}(9)-\mathrm{N}(2)$ & $1.377(4)$ & $\mathrm{C}(27)-\mathrm{H}(27 \mathrm{~A})$ & 0.9800 \\
\hline$C(9)-C(10)$ & $1.405(5)$ & $\mathrm{C}(27)-\mathrm{H}(27 \mathrm{~B})$ & 0.9800 \\
\hline$C(10)-C(1) \# 1$ & $1.411(5)$ & $\mathrm{C}(27)-\mathrm{H}(27 \mathrm{C})$ & 0.9800 \\
\hline$C(10)-C(20)$ & $1.488(5)$ & $C(28)-S(6)$ & $1.797(4)$ \\
\hline$C(11)-C(16)$ & $1.389(5)$ & $\mathrm{C}(28)-\mathrm{H}(28 \mathrm{~A})$ & 0.9800 \\
\hline$C(11)-C(12)$ & $1.391(5)$ & $\mathrm{C}(28)-\mathrm{H}(28 \mathrm{~B})$ & 0.9800 \\
\hline$C(12)-C(13)$ & $1.400(4)$ & $\mathrm{C}(28)-\mathrm{H}(28 \mathrm{C})$ & 0.9800 \\
\hline $\mathrm{C}(12)-\mathrm{H}(12)$ & 0.9500 & $C(29)-C(30)$ & $1.355(7)$ \\
\hline
\end{tabular}




\begin{tabular}{|c|c|}
\hline$C(29)-C(34)$ & $1.434(7)$ \\
\hline $\mathrm{C}(29)-\mathrm{N}(3)$ & $1.474(6)$ \\
\hline$C(30)-C(31)$ & $1.351(7)$ \\
\hline $\mathrm{C}(30)-\mathrm{H}(30)$ & 0.9500 \\
\hline$C(31)-C(32)$ & $1.380(7)$ \\
\hline $\mathrm{C}(31)-\mathrm{H}(31)$ & 0.9500 \\
\hline$C(32)-C(33)$ & $1.371(6)$ \\
\hline $\mathrm{C}(32)-\mathrm{H}(32)$ & 0.9500 \\
\hline$C(33)-C(34)$ & $1.382(7)$ \\
\hline $\mathrm{C}(33)-\mathrm{H}(33)$ & 0.9500 \\
\hline $\mathrm{C}(34)-\mathrm{H}(34)$ & 0.9500 \\
\hline$C(35)-C(36)$ & $1.381(5)$ \\
\hline$C(35)-C(40)$ & $1.384(6)$ \\
\hline $\mathrm{C}(35)-\mathrm{N}(4)$ & $1.457(5)$ \\
\hline$C(36)-C(37)$ & $1.379(5)$ \\
\hline $\mathrm{C}(36)-\mathrm{H}(36)$ & 0.9500 \\
\hline$C(37)-C(38)$ & $1.384(6)$ \\
\hline $\mathrm{C}(37)-\mathrm{H}(37)$ & 0.9500 \\
\hline$C(38)-C(39)$ & $1.371(6)$ \\
\hline $\mathrm{C}(38)-\mathrm{H}(38)$ & 0.9500 \\
\hline$C(39)-C(40)$ & $1.387(7)$ \\
\hline $\mathrm{C}(39)-\mathrm{H}(39)$ & 0.9500 \\
\hline $\mathrm{C}(40)-\mathrm{H}(40)$ & 0.9500 \\
\hline $\mathrm{N}(4)-\mathrm{O}(3)$ & $1.230(5)$ \\
\hline $\mathrm{N}(4)-\mathrm{O}(4)$ & $1.235(5)$ \\
\hline$C(41)-C(46)$ & $1.338(9)$ \\
\hline$C(41)-C(42)$ & $1.365(9)$ \\
\hline $\mathrm{C}(41)-\mathrm{H}(41)$ & 0.9500 \\
\hline$C(42)-C(43)$ & $1.353(11)$ \\
\hline $\mathrm{C}(42)-\mathrm{H}(42)$ & 0.9500 \\
\hline$C(43)-C(44)$ & $1.324(12)$ \\
\hline $\mathrm{C}(43)-\mathrm{H}(43)$ & 0.9500 \\
\hline$C(44)-C(45)$ & $1.376(13)$ \\
\hline $\mathrm{C}(44)-\mathrm{H}(44)$ & 0.9500 \\
\hline$C(45)-C(46)$ & $1.371(12)$ \\
\hline $\mathrm{C}(45)-\mathrm{H}(45)$ & 0.9500 \\
\hline $\mathrm{C}(46)-\mathrm{H}(46)$ & 0.9500 \\
\hline$C(47)-C(52)$ & $1.364(7)$ \\
\hline$C(47)-C(48)$ & $1.375(7)$ \\
\hline $\mathrm{C}(47)-\mathrm{H}(47)$ & 0.9500 \\
\hline$C(48)-C(49)$ & $1.392(6)$ \\
\hline $\mathrm{C}(48)-\mathrm{H}(48)$ & 0.9500 \\
\hline$C(49)-C(50)$ & $1.390(6)$ \\
\hline $\mathrm{C}(49)-\mathrm{H}(49)$ & 0.9500 \\
\hline$C(50)-C(51)$ & $1.367(7)$ \\
\hline $\mathrm{C}(50)-\mathrm{H}(50)$ & 0.9500 \\
\hline$C(51)-C(52)$ & $1.386(7)$ \\
\hline $\mathrm{C}(51)-\mathrm{H}(51)$ & 0.9500 \\
\hline $\mathrm{C}(52)-\mathrm{H}(52)$ & 0.9500 \\
\hline $\mathrm{N}(1)-\mathrm{Zn}(1)$ & $2.031(3)$ \\
\hline $\mathrm{N}(2)-\mathrm{Zn}(1)$ & $2.043(3)$ \\
\hline$N(3)-O(1)$ & $1.205(6)$ \\
\hline $\mathrm{N}(3)-\mathrm{O}(2)$ & $1.240(6)$ \\
\hline $\mathrm{Zn}(1)-\mathrm{N}(1) \# 1$ & $2.031(3)$ \\
\hline $\mathrm{Zn}(1)-\mathrm{N}(2) \# 1$ & $2.043(3)$ \\
\hline
\end{tabular}

$\mathrm{Br}(3)-\mathrm{Bi}(1)-\mathrm{Br}(2)$

$\mathrm{Br}(3)-\mathrm{Bi}(1)-\mathrm{Br}(1)$

$\mathrm{Br}(2)-\mathrm{B} i(1)-\mathrm{Br}(1)$

$\mathrm{Br}(3)-\mathrm{Bi}(1)-\mathrm{S}(1)$

$\mathrm{Br}(2)-\mathrm{Bi}(1)-\mathrm{S}(1)$

\begin{tabular}{|c|c|c|}
\hline $4(7)$ & $\mathrm{Br}(1)-\mathrm{Bi}(1)-\mathrm{S}(1)$ & $171.44(2)$ \\
\hline $4(6)$ & $\mathrm{Br}(3)-\mathrm{Bi}(1)-\mathrm{S}(2)$ & $116.605(19)$ \\
\hline $1(7)$ & $\mathrm{Br}(2)-\mathrm{Bi}(1)-\mathrm{S}(2)$ & $117.17(2)$ \\
\hline 00 & $\mathrm{Br}(1)-\mathrm{Bi}(1)-\mathrm{S}(2)$ & $133.664(18)$ \\
\hline $0(7)$ & $S(1)-B i(1)-S(2)$ & $54.18(2)$ \\
\hline 00 & $\mathrm{Br}(4)-\mathrm{Bi}(2)-\mathrm{Br}(6)$ & $94.525(19)$ \\
\hline $1(6)$ & $\mathrm{Br}(4)-\mathrm{Bi}(2)-\mathrm{Br}(5)$ & $91.822(15)$ \\
\hline 00 & $\mathrm{Br}(6)-\mathrm{Bi}(2)-\mathrm{Br}(5)$ & $92.007(14)$ \\
\hline $2(7)$ & $\mathrm{Br}(4)-\mathrm{Bi}(2)-\mathrm{O}(3)$ & $75.13(6)$ \\
\hline 00 & $\mathrm{Br}(6)-\mathrm{Bi}(2)-\mathrm{O}(3)$ & $119.90(6)$ \\
\hline 0 & $\mathrm{Br}(5)-\mathrm{Bi}(2)-\mathrm{O}(3)$ & $145.90(6)$ \\
\hline $1(5)$ & $\mathrm{Br}(4)-\mathrm{Bi}(2)-\mathrm{O}(4)$ & $71.91(6)$ \\
\hline $4(6)$ & $\mathrm{Br}(6)-\mathrm{Bi}(2)-\mathrm{O}(4)$ & $79.56(7)$ \\
\hline $7(5)$ & $\mathrm{Br}(5)-\mathrm{Bi}(2)-\mathrm{O}(4)$ & $160.80(6)$ \\
\hline $9(5)$ & $\mathrm{O}(3)-\mathrm{Bi}(2)-\mathrm{O}(4)$ & $40.61(9)$ \\
\hline 00 & $\operatorname{Br}(4)-B i(2)-S(3)$ & $80.41(2)$ \\
\hline $4(6)$ & $B r(6)-B i(2)-S(3)$ & $174.61(2)$ \\
\hline 00 & $\mathrm{Br}(5)-\mathrm{Bi}(2)-\mathrm{S}(3)$ & $90.032(19)$ \\
\hline $1(6)$ & $\mathrm{O}(3)-\mathrm{Bi}(2)-\mathrm{S}(3)$ & $57.13(6)$ \\
\hline 00 & $\mathrm{O}(4)-\mathrm{Bi}(2)-\mathrm{S}(3)$ & $96.99(7)$ \\
\hline $7(7)$ & $\operatorname{Br}(4)-B i(2)-S(2)$ & $127.600(18)$ \\
\hline 00 & $\operatorname{Br}(6)-B i(2)-S(2)$ & 132.311 (19) \\
\hline 00 & $B r(5)-B i(2)-S(2)$ & $68.343(18)$ \\
\hline $0(5)$ & $\mathrm{O}(3)-\mathrm{Bi}(2)-\mathrm{S}(2)$ & $94.60(6)$ \\
\hline $5(5)$ & $\mathrm{O}(4)-\mathrm{Bi}(2)-\mathrm{S}(2)$ & $129.67(7)$ \\
\hline $8(9)$ & $S(3)-B i(2)-S(2)$ & $53.06(2)$ \\
\hline $5(9)$ & $N(1)-C(1)-C(10) \# 1$ & $125.3(3)$ \\
\hline 0 & $N(1)-C(1)-C(2)$ & $110.3(3)$ \\
\hline $3(11)$ & $C(10) \# 1-C(1)-C(2)$ & $124.4(3)$ \\
\hline 00 & $C(3)-C(2)-C(1)$ & $107.0(3)$ \\
\hline $4(12)$ & $\mathrm{C}(3)-\mathrm{C}(2)-\mathrm{H}(2)$ & 126.5 \\
\hline 00 & $\mathrm{C}(1)-\mathrm{C}(2)-\mathrm{H}(2)$ & 126.5 \\
\hline $6(13)$ & $C(2)-C(3)-C(4)$ & $107.1(3)$ \\
\hline 00 & $\mathrm{C}(2)-\mathrm{C}(3)-\mathrm{H}(3)$ & 126.4 \\
\hline $1(12)$ & $\mathrm{C}(4)-\mathrm{C}(3)-\mathrm{H}(3)$ & 126.4 \\
\hline 0 & $N(1)-C(4)-C(5)$ & $125.2(3)$ \\
\hline 0 & $N(1)-C(4)-C(3)$ & $109.6(3)$ \\
\hline $4(7)$ & $C(5)-C(4)-C(3)$ & $125.2(3)$ \\
\hline $5(7)$ & $C(6)-C(5)-C(4)$ & $126.4(3)$ \\
\hline 00 & $C(6)-C(5)-C(11)$ & $115.8(3)$ \\
\hline $2(6)$ & $C(4)-C(5)-C(11)$ & $117.8(3)$ \\
\hline 00 & $N(2)-C(6)-C(5)$ & $125.3(3)$ \\
\hline (6) & $N(2)-C(6)-C(7)$ & $109.7(3)$ \\
\hline 0 & $C(5)-C(6)-C(7)$ & $125.0(3)$ \\
\hline $7(7)$ & $C(8)-C(7)-C(6)$ & $107.3(3)$ \\
\hline 0 & $\mathrm{C}(8)-\mathrm{C}(7)-\mathrm{H}(7)$ & 126.4 \\
\hline $6(7)$ & $\mathrm{C}(6)-\mathrm{C}(7)-\mathrm{H}(7)$ & 126.4 \\
\hline & $C(7)-C(8)-C(9)$ & $107.0(3)$ \\
\hline & $\mathrm{C}(7)-\mathrm{C}(8)-\mathrm{H}(8)$ & 126.5 \\
\hline (3) & $\mathrm{C}(9)-\mathrm{C}(8)-\mathrm{H}(8)$ & 126.5 \\
\hline (3) & $N(2)-C(9)-C(10)$ & $125.0(3)$ \\
\hline (6) & $N(2)-C(9)-C(8)$ & $109.6(3)$ \\
\hline (6) & $C(10)-C(9)-C(8)$ & $125.3(3)$ \\
\hline (3) & $C(9)-C(10)-C(1) \# 1$ & $125.2(3)$ \\
\hline$(3)$ & $C(9)-C(10)-C(20)$ & $116.5(3)$ \\
\hline & $C(1) \# 1-C(10)-C(20)$ & $118.3(3)$ \\
\hline $94.291(17)$ & $C(16)-C(11)-C(12)$ & $120.3(3)$ \\
\hline $92.748(17)$ & $C(16)-C(11)-C(5)$ & $121.7(3)$ \\
\hline $3.577(17)$ & $C(12)-C(11)-C(5)$ & $117.9(3)$ \\
\hline $84.86(2)$ & $C(11)-C(12)-C(13)$ & $120.2(3)$ \\
\hline $78.43(2)$ & $\mathrm{C}(11)-\mathrm{C}(12)-\mathrm{H}(12)$ & 119.9 \\
\hline
\end{tabular}




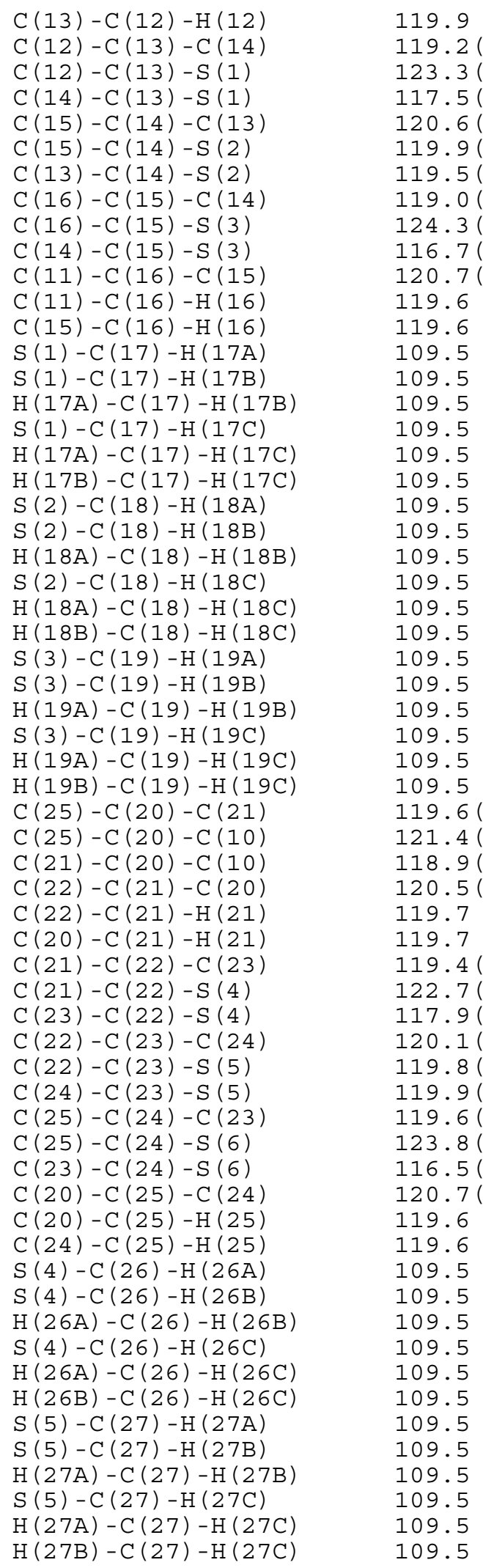

109.5
109.5

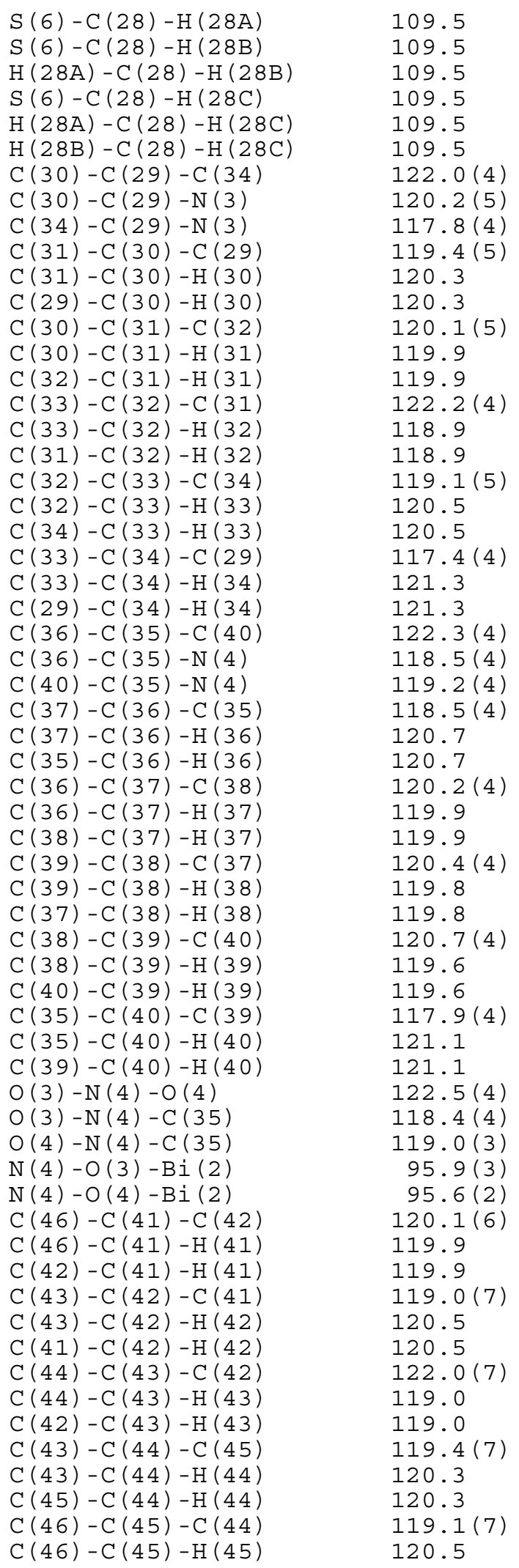




\begin{tabular}{|c|c|}
\hline $\mathrm{C}(44)-\mathrm{C}(45)-\mathrm{H}(45)$ & 120.5 \\
\hline$C(41)-C(46)-C(45)$ & $120.4(7)$ \\
\hline $\mathrm{C}(41)-\mathrm{C}(46)-\mathrm{H}(46)$ & 119.8 \\
\hline $\mathrm{C}(45)-\mathrm{C}(46)-\mathrm{H}(46)$ & 119.8 \\
\hline$C(52)-C(47)-C(48)$ & $120.7(4)$ \\
\hline $\mathrm{C}(52)-\mathrm{C}(47)-\mathrm{H}(47)$ & 119.6 \\
\hline $\mathrm{C}(48)-\mathrm{C}(47)-\mathrm{H}(47)$ & 119.6 \\
\hline$C(47)-C(48)-C(49)$ & $119.4(4)$ \\
\hline $\mathrm{C}(47)-\mathrm{C}(48)-\mathrm{H}(48)$ & 120.3 \\
\hline $\mathrm{C}(49)-\mathrm{C}(48)-\mathrm{H}(48)$ & 120.3 \\
\hline$C(50)-C(49)-C(48)$ & $119.6(4)$ \\
\hline $\mathrm{C}(50)-\mathrm{C}(49)-\mathrm{H}(49)$ & 120.2 \\
\hline $\mathrm{C}(48)-\mathrm{C}(49)-\mathrm{H}(49)$ & 120.2 \\
\hline$C(51)-C(50)-C(49)$ & $120.2(4)$ \\
\hline $\mathrm{C}(51)-\mathrm{C}(50)-\mathrm{H}(50)$ & 119.9 \\
\hline $\mathrm{C}(49)-\mathrm{C}(50)-\mathrm{H}(50)$ & 119.9 \\
\hline$C(50)-C(51)-C(52)$ & $119.9(4)$ \\
\hline $\mathrm{C}(50)-\mathrm{C}(51)-\mathrm{H}(51)$ & 120.1 \\
\hline $\mathrm{C}(52)-\mathrm{C}(51)-\mathrm{H}(51)$ & 120.1 \\
\hline$C(47)-C(52)-C(51)$ & $120.2(5)$ \\
\hline $\mathrm{C}(47)-\mathrm{C}(52)-\mathrm{H}(52)$ & 119.9 \\
\hline $\mathrm{C}(51)-\mathrm{C}(52)-\mathrm{H}(52)$ & 119.9 \\
\hline $\mathrm{C}(1)-\mathrm{N}(1)-\mathrm{C}(4)$ & $106.0(3)$ \\
\hline $\mathrm{C}(1)-\mathrm{N}(1)-\operatorname{Zn}(1)$ & $127.8(2)$ \\
\hline $\mathrm{C}(4)-\mathrm{N}(1)-\operatorname{Zn}(1)$ & $126.2(2)$ \\
\hline$C(9)-N(2)-C(6)$ & $106.4(3)$ \\
\hline$C(9)-N(2)-\operatorname{Zn}(1)$ & $127.3(2)$ \\
\hline$C(6)-N(2)-\operatorname{Zn}(1)$ & $126.3(2)$ \\
\hline$O(1)-N(3)-O(2)$ & $124.2(5)$ \\
\hline$O(1)-N(3)-C(29)$ & $118.6(5)$ \\
\hline $\mathrm{O}(2)-\mathrm{N}(3)-\mathrm{C}(29)$ & $117.2(5)$ \\
\hline$C(13)-S(1)-C(17)$ & $102.83(18)$ \\
\hline $\mathrm{C}(13)-\mathrm{S}(1)-\mathrm{Bi}(1)$ & $105.12(12)$ \\
\hline $\mathrm{C}(17)-\mathrm{S}(1)-\mathrm{Bi}(1)$ & $107.13(15)$ \\
\hline$C(14)-S(2)-C(18)$ & $99.63(17)$ \\
\hline$C(14)-S(2)-B i(2)$ & $95.47(12)$ \\
\hline$C(18)-S(2)-B i(2)$ & $136.27(17)$ \\
\hline $\mathrm{C}(14)-\mathrm{S}(2)-\mathrm{Bi}(1)$ & $94.43(12)$ \\
\hline $\mathrm{C}(18)-\mathrm{S}(2)-\mathrm{Bi}(1)$ & $130.01(16)$ \\
\hline $\mathrm{Bi}(2)-\mathrm{S}(2)-\mathrm{Bi}(1)$ & $88.92(2)$ \\
\hline$C(15)-S(3)-C(19)$ & $103.21(18)$ \\
\hline$C(15)-S(3)-B i(2)$ & $103.17(12)$ \\
\hline$C(19)-S(3)-B i(2)$ & $114.06(17)$ \\
\hline$C(22)-S(4)-C(26)$ & $102.71(18)$ \\
\hline$C(23)-S(5)-C(27)$ & $102.09(17)$ \\
\hline$C(24)-S(6)-C(28)$ & $103.77(17)$ \\
\hline $\mathrm{N}(1)-\mathrm{Zn}(1)-\mathrm{N}(1) \# 1$ & $180.00(13)$ \\
\hline $\mathrm{N}(1)-\mathrm{Zn}(1)-\mathrm{N}(2)$ & $90.52(11)$ \\
\hline $\mathrm{N}(1) \# 1-\operatorname{Zn}(1)-\mathrm{N}(2)$ & $89.48(11)$ \\
\hline $\mathrm{N}(1)-\operatorname{Zn}(1)-\mathrm{N}(2) \# 1$ & $89.48(11)$ \\
\hline $\mathrm{N}(1) \# 1-\operatorname{Zn}(1)-\mathrm{N}(2) \# 1$ & $90.52(11)$ \\
\hline $\mathrm{N}(2)-\mathrm{Zn}(1)-\mathrm{N}(2) \# 1$ & $180.000(1)$ \\
\hline
\end{tabular}


Symmetry transformations used to generate equivalent atoms:

$\# 1-x+1,-y+1,-z+2 \quad \# 2 x-0.5,0.5-y, z-0.5$

Table S4. Anisotropic displacement parameters $\left[\AA^{2} \times 10^{3}\right]$ for 2 . The anisotropic displacement factor exponent takes the form: $-2 \pi 2\left[\left(\mathrm{~h} \mathrm{a}^{*}\right)^{2}\right.$ U11 + $\left.\ldots+2 h k a^{*} b^{*} \mathrm{U} 12\right]$

\begin{tabular}{|c|c|c|c|c|c|c|}
\hline & U11 & U22 & U33 & U23 & U13 & U12 \\
\hline $\mathrm{Bi}(1)$ & $19(1)$ & $16(1)$ & $13(1)$ & $-1(1)$ & $3(1)$ & $-1(1)$ \\
\hline $\mathrm{Bi}(2)$ & $18(1)$ & $16(1)$ & $20(1)$ & $-5(1)$ & $9(1)$ & $-4(1)$ \\
\hline $\operatorname{Br}(1)$ & $25(1)$ & $33(1)$ & $27(1)$ & $0(1)$ & $-2(1)$ & $9(1)$ \\
\hline $\operatorname{Br}(2)$ & $29(1)$ & $28(1)$ & $16(1)$ & $6(1)$ & $5(1)$ & $-2(1)$ \\
\hline $\operatorname{Br}(3)$ & $31(1)$ & $34(1)$ & $25(1)$ & $-15(1)$ & $8(1)$ & $-11(1)$ \\
\hline $\operatorname{Br}(4)$ & $41(1)$ & $28(1)$ & $35(1)$ & $-3(1)$ & $19(1)$ & $-16(1)$ \\
\hline $\operatorname{Br}(5)$ & $27(1)$ & $21(1)$ & $21(1)$ & $-6(1)$ & $9(1)$ & $-7(1)$ \\
\hline $\operatorname{Br}(6)$ & $16(1)$ & $30(1)$ & $45(1)$ & $-8(1)$ & $12(1)$ & $-2(1)$ \\
\hline$C(1)$ & $13(2)$ & $12(2)$ & $15(2)$ & $-1(1)$ & $1(1)$ & $1(1)$ \\
\hline$C(2)$ & $17(2)$ & $15(2)$ & $22(2)$ & $-3(1)$ & $-2(1)$ & $1(1)$ \\
\hline$C(3)$ & $17(2)$ & $9(2)$ & $24(2)$ & $-3(1)$ & $0(1)$ & $0(1)$ \\
\hline$C(4)$ & $13(2)$ & $9(1)$ & $16(2)$ & $-4(1)$ & $2(1)$ & $-1(1)$ \\
\hline$C(5)$ & $19(2)$ & $6(1)$ & $15(2)$ & $-1(1)$ & $4(1)$ & $0(1)$ \\
\hline$C(6)$ & $14(2)$ & $12(2)$ & $15(2)$ & $1(1)$ & $4(1)$ & $1(1)$ \\
\hline$C(7)$ & $18(2)$ & $9(2)$ & $20(2)$ & $-1(1)$ & $5(1)$ & $2(1)$ \\
\hline$C(8)$ & $17(2)$ & $13(2)$ & $18(2)$ & $1(1)$ & $4(1)$ & $3(1)$ \\
\hline$C(9)$ & $14(2)$ & $11(2)$ & $13(2)$ & $1(1)$ & $2(1)$ & $1(1)$ \\
\hline$C(10)$ & $12(2)$ & $11(2)$ & $16(2)$ & $0(1)$ & $1(1)$ & $1(1)$ \\
\hline$C(11)$ & $10(2)$ & $11(2)$ & $15(2)$ & $-2(1)$ & $0(1)$ & $3(1)$ \\
\hline$C(12)$ & $12(2)$ & $13(2)$ & $16(2)$ & $-3(1)$ & $3(1)$ & $1(1)$ \\
\hline$C(13)$ & $14(2)$ & $9(2)$ & $19(2)$ & $2(1)$ & $5(1)$ & $1(1)$ \\
\hline$C(14)$ & $17(2)$ & $9(2)$ & $18(2)$ & $-3(1)$ & $2(1)$ & $1(1)$ \\
\hline$C(15)$ & $18(2)$ & $12(2)$ & $15(2)$ & $-2(1)$ & $5(1)$ & $2(1)$ \\
\hline$C(16)$ & $17(2)$ & $10(2)$ & $18(2)$ & $3(1)$ & $4(1)$ & $1(1)$ \\
\hline$C(17)$ & $48(3)$ & $22(2)$ & $25(2)$ & $1(2)$ & $22(2)$ & $4(2)$ \\
\hline$C(18)$ & $28(2)$ & $17(2)$ & $41(3)$ & $-9(2)$ & $-2(2)$ & $-1(2)$ \\
\hline$C(19)$ & $60(3)$ & $20(2)$ & $33(2)$ & $5(2)$ & $28(2)$ & $9(2)$ \\
\hline$C(20)$ & $15(2)$ & $8(1)$ & $14(2)$ & $0(1)$ & 1 (1) & $1(1)$ \\
\hline$C(21)$ & $14(2)$ & $11(2)$ & $16(2)$ & $-2(1)$ & $2(1)$ & $2(1)$ \\
\hline$C(22)$ & $18(2)$ & $7(1)$ & $16(2)$ & $0(1)$ & $4(1)$ & $0(1)$ \\
\hline$C(23)$ & $12(2)$ & $8(1)$ & $15(2)$ & $0(1)$ & $-2(1)$ & $1(1)$ \\
\hline$C(24)$ & $15(2)$ & $11(2)$ & $15(2)$ & $2(1)$ & $5(1)$ & $-1(1)$ \\
\hline$C(25)$ & $18(2)$ & $12(2)$ & $17(2)$ & $1(1)$ & $1(1)$ & $-2(1)$ \\
\hline$C(26)$ & $24(2)$ & $35(2)$ & $21(2)$ & $-2(2)$ & $7(2)$ & $4(2)$ \\
\hline C (27) & $20(2)$ & $22(2)$ & $34(2)$ & $6(2)$ & $-2(2)$ & $-10(2)$ \\
\hline$C(28)$ & $27(2)$ & $32(2)$ & $17(2)$ & $5(2)$ & $8(2)$ & $10(2)$ \\
\hline$C(29)$ & $40(2)$ & $26(2)$ & $36(2)$ & $10(2)$ & $26(2)$ & $11(2)$ \\
\hline$C(30)$ & $39(3)$ & $42(3)$ & $29(2)$ & $9(2)$ & $12(2)$ & $0(2)$ \\
\hline$C(31)$ & $36(2)$ & $43(3)$ & $32(2)$ & $8(2)$ & $11(2)$ & $4(2)$ \\
\hline$C(32)$ & $37(2)$ & $33(2)$ & $33(2)$ & $3(2)$ & $17(2)$ & $1(2)$ \\
\hline$C(33)$ & $34(2)$ & $35(2)$ & $34(2)$ & $0(2)$ & $11(2)$ & $-2(2)$ \\
\hline$C(34)$ & $31(2)$ & $61(3)$ & $35(3)$ & $16(2)$ & $11(2)$ & $5(2)$ \\
\hline$C(35)$ & $27(2)$ & $19(2)$ & $20(2)$ & $-5(1)$ & $8(2)$ & $-5(2)$ \\
\hline$C(36)$ & $20(2)$ & $24(2)$ & $22(2)$ & $3(2)$ & $4(2)$ & $2(2)$ \\
\hline
\end{tabular}




\begin{tabular}{|c|c|c|c|c|c|c|}
\hline$C(37)$ & $28(2)$ & $29(2)$ & $22(2)$ & $1(2)$ & $10(2)$ & $2(2)$ \\
\hline$C(38)$ & $32(2)$ & $23(2)$ & $22(2)$ & $1(2)$ & $3(2)$ & $-2(2)$ \\
\hline$C(39)$ & $36(2)$ & $23(2)$ & $43(3)$ & $3(2)$ & $9(2)$ & $8(2)$ \\
\hline$C(40)$ & $34(2)$ & $31(2)$ & $36(2)$ & $-7(2)$ & $16(2)$ & $6(2)$ \\
\hline$N(4)$ & $36(2)$ & $28(2)$ & $26(2)$ & $-8(2)$ & $16(2)$ & $-12(2)$ \\
\hline$O(3)$ & $51(2)$ & $40(2)$ & $38(2)$ & $-11(2)$ & $30(2)$ & $-12(2)$ \\
\hline$O(4)$ & $46(2)$ & $41(2)$ & $24(2)$ & $7(1)$ & $9(1)$ & $-10(2)$ \\
\hline$C(41)$ & $68(4)$ & $66(4)$ & $40(3)$ & $-11(3)$ & $13(3)$ & $0(3)$ \\
\hline$C(42)$ & $39(3)$ & $72(4)$ & $93(6)$ & $-23(4)$ & $-1(3)$ & $8(3)$ \\
\hline$C(43)$ & $101(6)$ & $67(5)$ & $114(7)$ & $-52(5)$ & $77(6)$ & $-38(4)$ \\
\hline$C(44)$ & $128(8)$ & $82(6)$ & $39(3)$ & $-2(4)$ & $15(4)$ & $-82(6)$ \\
\hline$C(45)$ & $59(5)$ & $78(5)$ & $107(7)$ & $64(5)$ & $-35(5)$ & $-40(4)$ \\
\hline$C(46)$ & $47(4)$ & $47(3)$ & $111(6)$ & $7(4)$ & $38(4)$ & $2(3)$ \\
\hline$C(47)$ & $38(3)$ & $24(2)$ & $38(3)$ & $4(2)$ & $3(2)$ & $-3(2)$ \\
\hline$C(48)$ & $35(2)$ & $24(2)$ & $34(2)$ & $-6(2)$ & $8(2)$ & $2(2)$ \\
\hline$C(49)$ & $30(2)$ & $28(2)$ & $29(2)$ & $-6(2)$ & $7(2)$ & $-9(2)$ \\
\hline$C(50)$ & $46(3)$ & $21(2)$ & $24(2)$ & $-5(2)$ & $2(2)$ & $-1(2)$ \\
\hline$C(51)$ & $41(3)$ & $40(3)$ & $23(2)$ & $-8(2)$ & $7(2)$ & $9(2)$ \\
\hline$C(52)$ & $39(3)$ & $46(3)$ & $24(2)$ & $2(2)$ & $10(2)$ & $-3(2)$ \\
\hline$N(1)$ & $15(1)$ & $8(1)$ & $14(1)$ & $-1(1)$ & $0(1)$ & $1(1)$ \\
\hline $\mathrm{N}(2)$ & $14(1)$ & $9(1)$ & $14(1)$ & $-1(1)$ & $3(1)$ & $0(1)$ \\
\hline $\mathrm{N}(3)$ & $56(3)$ & $52(3)$ & $56(3)$ & $25(2)$ & $37(3)$ & $20(2)$ \\
\hline$O(1)$ & $98(3)$ & $34(2)$ & $59(3)$ & $-8(2)$ & $49(3)$ & $0(2)$ \\
\hline$O(2)$ & $64(3)$ & $73(3)$ & $83(3)$ & $34(3)$ & $29(3)$ & $39(2)$ \\
\hline$S(1)$ & $24(1)$ & $12(1)$ & $21(1)$ & $3(1)$ & $10(1)$ & $1(1)$ \\
\hline$S(2)$ & $24(1)$ & $8(1)$ & $20(1)$ & $-2(1)$ & $7(1)$ & $3(1)$ \\
\hline$S(3)$ & $33(1)$ & $14(1)$ & $17(1)$ & $0(1)$ & $11(1)$ & $5(1)$ \\
\hline$S(4)$ & $18(1)$ & $18(1)$ & $14(1)$ & $-2(1)$ & $1(1)$ & $4(1)$ \\
\hline$S(5)$ & $12(1)$ & $13(1)$ & $17(1)$ & $3(1)$ & $0(1)$ & $0(1)$ \\
\hline$S(6)$ & $15(1)$ & $18(1)$ & $17(1)$ & $4(1)$ & $4(1)$ & $3(1)$ \\
\hline Zn (1) & 12 (1) & $8(1)$ & $14(1)$ & $-2(1)$ & $0(1)$ & $1(1)$ \\
\hline
\end{tabular}

Table 55. Hydrogen coordinates $\left(\times 10^{4}\right)$ and isotropic displacement parameters $\left(\AA^{2} \times 10^{3}\right)$ for 2 .

\begin{tabular}{|c|c|c|c|c|}
\hline & $x$ & $y$ & z & $\mathrm{U}(\mathrm{eq})$ \\
\hline $\mathrm{H}(2)$ & 1768 & 4398 & 7844 & 23 \\
\hline $\mathrm{H}(3)$ & 2935 & 3704 & 8027 & 21 \\
\hline $\mathrm{H}(7)$ & 6603 & 3321 & 9991 & 19 \\
\hline $\mathrm{H}(8)$ & 7938 & 3790 & 11002 & 19 \\
\hline $\mathrm{H}(12)$ & 4608 & 3063 & 10041 & 17 \\
\hline $\mathrm{H}(16)$ & 4860 & 3452 & 7779 & 18 \\
\hline $\mathrm{H}(17 \mathrm{~A})$ & 5115 & 2509 & 11067 & 44 \\
\hline $\mathrm{H}(17 \mathrm{~B})$ & 4481 & 2082 & 11315 & 44 \\
\hline $\mathrm{H}(17 \mathrm{C})$ & 3913 & 2537 & 10799 & 44 \\
\hline $\mathrm{H}(18 \mathrm{~A})$ & 3043 & 1698 & 8153 & 47 \\
\hline $\mathrm{H}(18 \mathrm{~B})$ & 3296 & 1314 & 7529 & 47 \\
\hline $\mathrm{H}(18 \mathrm{C})$ & 3156 & 1872 & 7273 & 47 \\
\hline $\mathrm{H}(19 \mathrm{~A})$ & 4504 & 3284 & 6382 & 52 \\
\hline $\mathrm{H}(19 \mathrm{~B})$ & 5187 & 3006 & 5908 & 52 \\
\hline $\mathrm{H}(19 \mathrm{C})$ & 5694 & 3248 & 6799 & 52 \\
\hline $\mathrm{H}(21)$ & 8131 & 4762 & 12862 & 17 \\
\hline $\mathrm{H}(25)$ & 9094 & 4528 & 10828 & 19 \\
\hline
\end{tabular}




\begin{tabular}{|c|c|c|c|c|}
\hline $\mathrm{H}(26 \mathrm{~A})$ & 8371 & 4891 & 14234 & 40 \\
\hline $\mathrm{H}(26 \mathrm{~B})$ & 8695 & 4518 & 14995 & 40 \\
\hline $\mathrm{H}(26 \mathrm{C})$ & 8185 & 4325 & 14067 & 40 \\
\hline $\mathrm{H}(27 \mathrm{~A})$ & 12402 & 4759 & 13008 & 41 \\
\hline $\mathrm{H}(27 \mathrm{~B})$ & 12968 & 4607 & 13949 & 41 \\
\hline $\mathrm{H}(27 \mathrm{C})$ & 12009 & 4955 & 13756 & 41 \\
\hline $\mathrm{H}(28 \mathrm{~A})$ & 10084 & 4031 & 10243 & 37 \\
\hline $\mathrm{H}(28 \mathrm{~B})$ & 11174 & 4168 & 10170 & 37 \\
\hline $\mathrm{H}(28 \mathrm{C})$ & 10426 & 4585 & 10284 & 37 \\
\hline $\mathrm{H}(30)$ & 6123 & 5832 & 9057 & 43 \\
\hline $\mathrm{H}(31)$ & 6866 & 5087 & 9074 & 44 \\
\hline $\mathrm{H}(32)$ & 6079 & 4496 & 8132 & 40 \\
\hline $\mathrm{H}(33)$ & 4547 & 4632 & 7149 & 41 \\
\hline $\mathrm{H}(34)$ & 3772 & 5393 & 7101 & 50 \\
\hline $\mathrm{H}(36)$ & 7618 & 1802 & 4440 & 27 \\
\hline $\mathrm{H}(37)$ & 7565 & 2144 & 3150 & 31 \\
\hline $\mathrm{H}(38)$ & 6360 & 2726 & 2556 & 32 \\
\hline $\mathrm{H}(39)$ & 5169 & 2948 & 3208 & 41 \\
\hline $\mathrm{H}(40)$ & 5206 & 2614 & 4505 & 39 \\
\hline $\mathrm{H}(41)$ & 5957 & 3779 & 4120 & 70 \\
\hline $\mathrm{H}(42)$ & 4990 & 4316 & 4624 & 87 \\
\hline $\mathrm{H}(43)$ & 5507 & 4534 & 6007 & 101 \\
\hline $\mathrm{H}(44)$ & 6957 & 4249 & 6884 & 102 \\
\hline $\mathrm{H}(45)$ & 7963 & 3726 & 6378 & 112 \\
\hline $\mathrm{H}(46)$ & 7432 & 3490 & 4986 & 78 \\
\hline $\mathrm{H}(47)$ & 5758 & 8141 & 6430 & 42 \\
\hline $\mathrm{H}(48)$ & 6990 & 8413 & 5851 & 37 \\
\hline $\mathrm{H}(49)$ & 7361 & 9241 & 5875 & 35 \\
\hline $\mathrm{H}(50)$ & 6475 & 9784 & 6472 & 38 \\
\hline $\mathrm{H}(51)$ & 5243 & 9504 & 7036 & 43 \\
\hline $\mathrm{H}(52)$ & 4855 & 8681 & 6979 & 44 \\
\hline
\end{tabular}




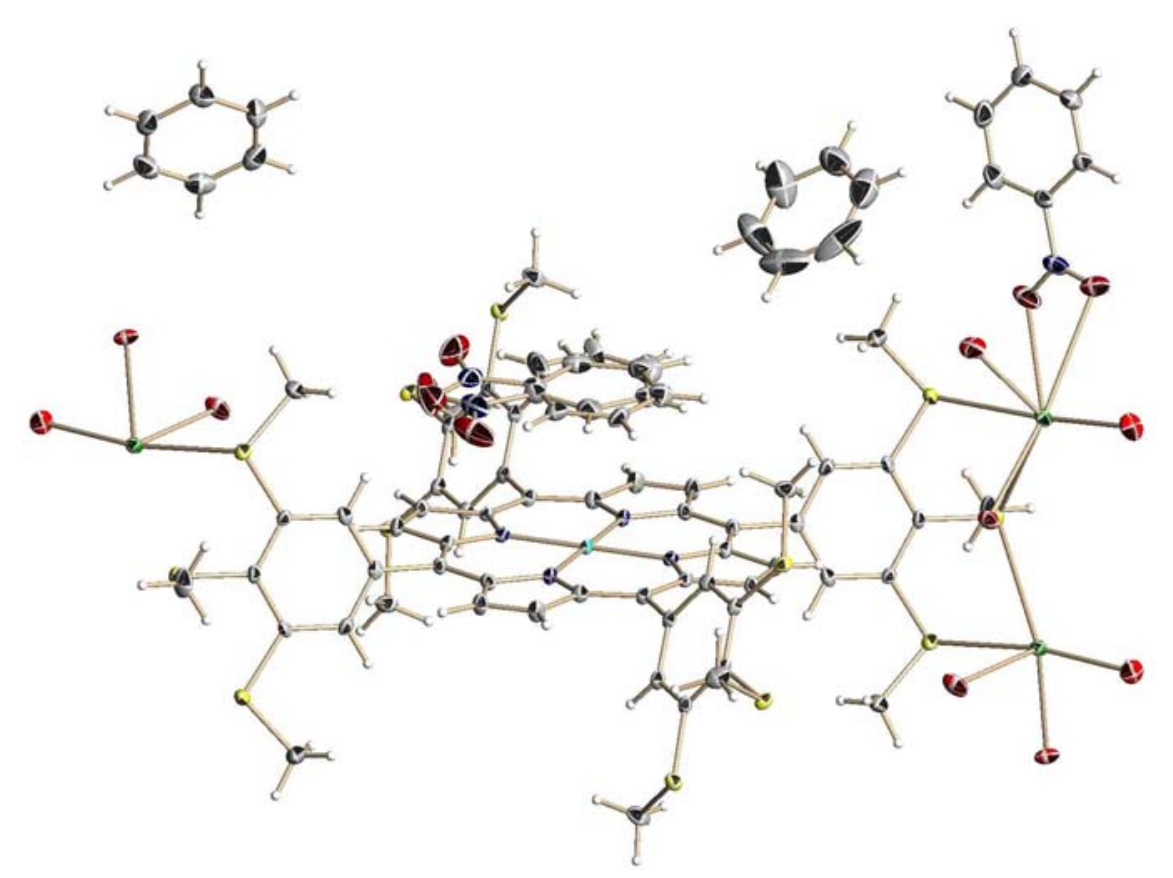

Figure S6. A thermal ellipsoid presentation of the crystal structure of 3.

Table s6. Crystal data and structure refinement for $\mathbf{3}$ :

Identification code: $05 \mathrm{mz} 084 \mathrm{~m}$

Empirical formula: C104 H96 Bi4 Br12 Cu N8 08 S12

Moiety formula: C56 H52 N4 S12 Cu, 4(C6 H5 N 02), 4(C6 H6), 4(Bi Br3)

Formula weight: 3828.99

Temperature: $100(2) \mathrm{K}$

Wavelength: $0.71073 \AA$

Crystal system: Monoclinic

Space group: $\mathrm{P} 2{ }_{1} / \mathrm{n}$

Unit cell dimensions:

$a=13.9490(19) \AA, \alpha=90^{\circ}$

$b=27.592(4) \AA, \beta=107.134(2)^{\circ}$

$c=16.714(2) \AA, \gamma=90^{\circ}$

Volume, $Z: 6147.4(14) \AA^{3}, 2$

Density (calculated): $2.069 \mathrm{Mg} / \mathrm{m}^{3}$

Absorption coefficient: $10.035 \mathrm{~mm}^{-1}$

$F(\odot 0 \odot): 3626$

Crystal size: $0.41 \times 0.35 \times 0.20 \mathrm{~mm}$

Crystal shape, color: block, red 
$\theta$ range for data collection: 1.68 to $28.28^{\circ}$

Limiting indices: $-18 \leq h \leq 18,-36 \leq k \leq 36,-22 \leq 1 \leq 22$

Reflections collected: 62876

Independent reflections: $15262(R($ int $)=0.0438)$

Completeness to $\theta=28.28^{\circ}: 100.0 \%$

Absorption correction: multi-scan

Max. and min. transmission: 0.134 and 0.031

Refinement method: Full-matrix least-squares on $F^{2}$

Data / restraints / parameters: 15262 / $13 / 737$

Goodness-of-fit on $F^{2}: 1.044$

Final $R$ indices $[I>2 \sigma(I)]: \mathrm{R} 1=0.0257, \mathrm{WR} 2=0.0566$

$R$ indices (all data): R1 $=0.0348, W R 2=0.0594$

Largest diff. peak and hole: 1.341 and $-0.811 \mathrm{e} \times \AA^{-3}$

Refinement of $F^{2}$ against ALL reflections. The weighted R-factor $\mathrm{wR}$ and goodness of fit are based on $F^{2}$, conventional R-factors $\mathrm{R}$ are based on $F$, with $F$ set to zero for negative $F^{2}$. The threshold expression of $F^{2}>2 \sigma\left(F^{2}\right)$ is used only for calculating R-factors.

\section{Comments:}

One of the nitrobenzene solvate molecules is disordered over two positions. Their aromatic rings were restraint to resemble an ideal hexagon using AFIX 66 commands and both nitro groups were restraint to have similar geometries using several SADI commands. The occupancy ratio refined to $\odot .687(5)$ to $\odot .313(5)$.

Treatment of hydrogen atoms:

All hydrogen atoms were placed in calculated positions and were refined with an isotropic displacement parameter 1.2 times that of the adjacent carbon atom.

Table s7. Atomic coordinates $\left[\times 10^{4}\right]$ and equivalent isotropic displacement parameters $\left[\AA^{2} \times 10^{3}\right]$ for $3 . \mathrm{U}(\mathrm{eq})$ is defined as one third of the trace of the orthogonalized $U_{i j}$ tensor.

\begin{tabular}{lrrrr}
\hline & x & y & z & U(eq $)$ \\
\hline $\operatorname{Bi}(1)$ & $6318(1)$ & $1388(1)$ & $10242(1)$ & $15(1)$ \\
$\operatorname{Bi}(2)$ & $6906(1)$ & $1848(1)$ & $7493(1)$ & $16(1)$ \\
$\operatorname{Br}(1)$ & $7930(1)$ & $816(1)$ & $10752(1)$ & $27(1)$ \\
$\operatorname{Br}(2)$ & $5447(1)$ & $1009(1)$ & $11311(1)$ & $23(1)$ \\
$\operatorname{Br}(3)$ & $7194(1)$ & $2097(1)$ & $11261(1)$ & $27(1)$ \\
$\operatorname{Br}(4)$ & $7687(1)$ & $2641(1)$ & $7083(1)$ & $30(1)$ \\
$\operatorname{Br}(5)$ & $7263(1)$ & $2146(1)$ & $9079(1)$ & $20(1)$ \\
$\operatorname{Br}(6)$ & $8607(1)$ & $1354(1)$ & $7865(1)$ & $27(1)$
\end{tabular}




\begin{tabular}{|c|c|c|c|c|}
\hline$C(1)$ & $2982(2)$ & $4771(1)$ & $8744(2)$ & $14(1)$ \\
\hline$C(2)$ & $2445(3)$ & $4390(1)$ & $8210(2)$ & $18(1)$ \\
\hline$C(3)$ & $3072(2)$ & 4009 (1) & $8314(2)$ & $17(1)$ \\
\hline$C(4)$ & $4001(2)$ & $4150(1)$ & $8919(2)$ & $13(1)$ \\
\hline$C(5)$ & $4820(2)$ & $3846(1)$ & $9227(2)$ & $13(1)$ \\
\hline$C(6)$ & $5711(2)$ & 3978 (1) & $9816(2)$ & $12(1)$ \\
\hline$C(7)$ & $6548(2)$ & $3658(1)$ & $10130(2)$ & $15(1)$ \\
\hline$C(8)$ & $7275(2)$ & $3914(1)$ & $10675(2)$ & $14(1)$ \\
\hline$C(9)$ & $6896(2)$ & 4397 (1) & $10700(2)$ & $12(1)$ \\
\hline$C(10)$ & $7422(2)$ & 4768 (1) & $11206(2)$ & $13(1)$ \\
\hline$C(11)$ & $4740(2)$ & $3331(1)$ & $8938(2)$ & $12(1)$ \\
\hline$C(12)$ & $4636(2)$ & $2973(1)$ & $9492(2)$ & $14(1)$ \\
\hline$C(13)$ & $4597(2)$ & 2488 (1) & $9260(2)$ & $13(1)$ \\
\hline$C(14)$ & $4678(2)$ & $2363(1)$ & $8475(2)$ & $14(1)$ \\
\hline$C(15)$ & $4781(2)$ & $2722(1)$ & $7916(2)$ & $14(1)$ \\
\hline$C(16)$ & $4795(2)$ & 3207 (1) & $8147(2)$ & $16(1)$ \\
\hline$C(17)$ & $4452(3)$ & 2319 (1) & $10872(2)$ & $27(1)$ \\
\hline$C(18)$ & $3368(3)$ & $1643(1)$ & $7719(3)$ & $30(1)$ \\
\hline$C(19)$ & $5056(4)$ & 3078 (1) & $6435(2)$ & $33(1)$ \\
\hline$C(20)$ & $8453(2)$ & $4658(1)$ & $11749(2)$ & $13(1)$ \\
\hline$C(21)$ & $8646(2)$ & $4664(1)$ & $12618(2)$ & $14(1)$ \\
\hline$C(22)$ & $9583(2)$ & 4521 (1) & $13145(2)$ & $13(1)$ \\
\hline$C(23)$ & $10332(2)$ & $4380(1)$ & $12794(2)$ & $13(1)$ \\
\hline$C(24)$ & $10153(2)$ & $4383(1)$ & $11921(2)$ & $13(1)$ \\
\hline$C(25)$ & $9213(2)$ & $4525(1)$ & $11405(2)$ & $14(1)$ \\
\hline$C(26)$ & $8643(3)$ & $4566(1)$ & $14405(2)$ & $24(1)$ \\
\hline$C(27)$ & $12317(3)$ & $4672(1)$ & $13560(2)$ & $24(1)$ \\
\hline$C(28)$ & $10646(3)$ & $4254(1)$ & $10423(2)$ & $23(1)$ \\
\hline$N(3)$ & $4455(4)$ & $6164(2)$ & $8056(3)$ & $35(1)$ \\
\hline$O(1)$ & $4903(10)$ & $6469(3)$ & $8556(7)$ & $46(3)$ \\
\hline$O(2)$ & $3664(4)$ & $6237(2)$ & $7514(3)$ & $52(2)$ \\
\hline$C(29)$ & $4899(4)$ & $5690(1)$ & $8081(3)$ & $19(2)$ \\
\hline$C(30)$ & $5830(4)$ & 5595 (1) & $8650(3)$ & $25(1)$ \\
\hline$C(31)$ & $6278(3)$ & $5145(2)$ & $8655(3)$ & $25(1)$ \\
\hline$C(32)$ & $5795(4)$ & 4789 (1) & $8090(4)$ & $30(2)$ \\
\hline$C(33)$ & $4864(4)$ & $4884(2)$ & $7521(4)$ & $28(3)$ \\
\hline$C(34)$ & $4416(3)$ & $5334(2)$ & $7516(3)$ & $28(1)$ \\
\hline$N(3 B)$ & $5255(11)$ & $6178(4)$ & $8656(8)$ & $46(4)$ \\
\hline$O(1 B)$ & $6023(9)$ & $6236(4)$ & $9231(7)$ & $60(4)$ \\
\hline$O(2 B)$ & $4600(20)$ & $6485(7)$ & $8450(20)$ & $68(9)$ \\
\hline$C(29 B)$ & $5155(10)$ & $5706(3)$ & $8270(7)$ & $20(4)$ \\
\hline$C(30 B)$ & $5864(8)$ & $5340(3)$ & $8522(6)$ & $32(4)$ \\
\hline$C(31 B)$ & $5695(9)$ & $4890(3)$ & $8131(9)$ & $25(4)$ \\
\hline$C(32 B)$ & $4818(10)$ & $4807(3)$ & $7487(10)$ & $33(6)$ \\
\hline$C(33 B)$ & $4109(7)$ & $5173(4)$ & $7235(7)$ & $28(3)$ \\
\hline$C(34 B)$ & $4278(8)$ & $5623(3)$ & $7627(7)$ & $42(4)$ \\
\hline$C(35)$ & $6390(3)$ & $2179(1)$ & $4554(2)$ & $19(1)$ \\
\hline$C(36)$ & $7105(3)$ & 2031 (1) & $4186(2)$ & $20(1)$ \\
\hline$C(37)$ & $7085(3)$ & 2235 (1) & $3426(2)$ & $23(1)$ \\
\hline$C(38)$ & 6361 (3) & 2576 (1) & $3054(2)$ & $26(1)$ \\
\hline$C(39)$ & $5659(3)$ & 2716 (1) & $3435(3)$ & $33(1)$ \\
\hline$C(40)$ & $5665(3)$ & 2522 (1) & 4199 (3) & $30(1)$ \\
\hline $\mathrm{N}(4)$ & $6396(3)$ & $1962(1)$ & $5353(2)$ & $28(1)$ \\
\hline$O(3)$ & $5689(2)$ & 2041 (1) & $5631(2)$ & $37(1)$ \\
\hline$O(4)$ & $7114(2)$ & 1705 (1) & $5724(2)$ & $34(1)$ \\
\hline$C(41)$ & $6158(4)$ & $3879(2)$ & $4675(3)$ & $52(1)$ \\
\hline$C(42)$ & $5577(4)$ & $4190(2)$ & $4963(4)$ & $69(2)$ \\
\hline$C(43)$ & $5872(5)$ & $4334(2)$ & $5770(5)$ & $77(2)$ \\
\hline$C(44)$ & $6715(7)$ & $4171(3)$ & $6292(4)$ & $82(3)$ \\
\hline$C(45)$ & $7317(5)$ & $3858(2)$ & $6033(5)$ & $80(3)$ \\
\hline$C(46)$ & $7029(4)$ & $3710(2)$ & $5202(4)$ & $63(2)$ \\
\hline
\end{tabular}




\begin{tabular}{lrrrr}
$C(47)$ & $5919(3)$ & $8474(1)$ & $6425(3)$ & $32(1)$ \\
$C(48)$ & $6654(3)$ & $8640(1)$ & $6097(3)$ & $30(1)$ \\
$C(49)$ & $6864(3)$ & $9131(1)$ & $6113(2)$ & $29(1)$ \\
$C(50)$ & $6339(3)$ & $9450(1)$ & $6466(2)$ & $31(1)$ \\
$C(51)$ & $5610(3)$ & $9281(2)$ & $6796(2)$ & $35(1)$ \\
$C(52)$ & $5393(3)$ & $8791(2)$ & $6770(2)$ & $34(1)$ \\
N $(1)$ & $3936(2)$ & $4624(1)$ & $9176(2)$ & $12(1)$ \\
N $(2)$ & $5930(2)$ & $4429(1)$ & $10174(2)$ & $12(1)$ \\
$S(1)$ & $4406(1)$ & $2013(1)$ & $9907(1)$ & $17(1)$ \\
$S(2)$ & $4697(1)$ & $1743(1)$ & $8198(1)$ & $17(1)$ \\
$S(3)$ & $4900(1)$ & $2523(1)$ & $6946(1)$ & $19(1)$ \\
$S(4)$ & $9861(1)$ & $4511(1)$ & $14246(1)$ & $16(1)$ \\
$S(5)$ & $11490(1)$ & $4152(1)$ & $13448(1)$ & $13(1)$ \\
$S(6)$ & $11154(1)$ & $4205(1)$ & $11545(1)$ & $16(1)$ \\
$C u(1)$ & 5000 & 5000 & 10000 & $10(1)$ \\
& & & & \\
\hline
\end{tabular}

All esds (except the esd in the dihedral angle between two 1.s. planes) are estimated using the full covariance matrix. The cell esds are taken into account individually in the estimation of esds in distances, angles and torsion angles; correlations between esds in cell parameters are only used when they are defined by crystal symmetry. An approximate (isotropic) treatment of cell esds is used for estimating esds involving l.s. planes.

Table s8. Bond lengths $[\AA]$ and angles [deg] for 3 .

\begin{tabular}{|c|c|c|c|}
\hline $\mathrm{Cu}(1)-\mathrm{C}(31)$ & $3.2797(51)$ & $\mathrm{C}(4)-\mathrm{N}(1)$ & $1.386(4)$ \\
\hline $\mathrm{Cu}(1)-\mathrm{C}(30)$ & $3.2668(47)$ & $C(4)-C(5)$ & $1.388(4)$ \\
\hline $\mathrm{Bi}(2)-\mathrm{S}(6) \# 2$ & $3.3290(8)$ & $C(5)-C(6)$ & $1.388(4)$ \\
\hline $\mathrm{Bi}(2)-\mathrm{S}(5) \# 2$ & $3.3245(9)$ & $C(5)-C(11)$ & $1.495(4)$ \\
\hline $\mathrm{Bi}(1)-\mathrm{S}(5) \# 2$ & $3.4205(9)$ & $\mathrm{C}(6)-\mathrm{N}(2)$ & $1.375(4)$ \\
\hline $\mathrm{Bi}(1)-\mathrm{S}(4) \# 2$ & $3.3273(8)$ & $C(6)-C(7)$ & $1.435(4)$ \\
\hline $\mathrm{Bi}(2)-\mathrm{O}(4)$ & $3.0806(28)$ & $C(7)-C(8)$ & $1.346(4)$ \\
\hline $\mathrm{Bi}(2)-\mathrm{O}(3)$ & $3.1207(31)$ & $\mathrm{C}(7)-\mathrm{H}(7)$ & 0.9500 \\
\hline $\mathrm{Bi}(2)-\mathrm{S}(2)$ & $3.6201(10)$ & $C(8)-C(9)$ & $1.441(4)$ \\
\hline $\mathrm{Bi}(2)-\mathrm{S}(3)$ & $3.2605(9)$ & $\mathrm{C}(8)-\mathrm{H}(8)$ & 0.9500 \\
\hline $\mathrm{Bi}(1)-\mathrm{Br}(3)$ & $2.6444(4)$ & $\mathrm{C}(9)-\mathrm{N}(2)$ & $1.377(4)$ \\
\hline $\mathrm{Bi}(1)-\mathrm{Br}(2)$ & $2.6531(4)$ & $C(9)-C(10)$ & $1.392(4)$ \\
\hline $\mathrm{Bi}(1)-\mathrm{Br}(1)$ & $2.6751(5)$ & $C(10)-C(1) \# 1$ & $1.403(4)$ \\
\hline $\mathrm{Bi}(1)-\mathrm{S}(1)$ & $3.0842(9)$ & $C(10)-C(20)$ & $1.488(4)$ \\
\hline $\mathrm{Bi}(1)-\mathrm{S}(2)$ & $3.6326(9)$ & $C(11)-C(16)$ & $1.388(4)$ \\
\hline $\mathrm{Bi}(2)-\mathrm{Br}(4)$ & $2.6221(4)$ & $C(11)-C(12)$ & $1.391(4)$ \\
\hline $\mathrm{Bi}(2)-\mathrm{Br}(6)$ & $2.6474(5)$ & $C(12)-C(13)$ & $1.391(4)$ \\
\hline $\mathrm{Bi}(2)-\mathrm{Br}(5)$ & $2.6781(5)$ & $\mathrm{C}(12)-\mathrm{H}(12)$ & 0.9500 \\
\hline $\mathrm{Bi}(2)-\mathrm{O}(4)$ & $3.081(3)$ & $C(13)-C(14)$ & $1.394(4)$ \\
\hline $\mathrm{Bi}(2)-\mathrm{O}(3)$ & $3.121(3)$ & $C(13)-S(1)$ & $1.767(3)$ \\
\hline $\mathrm{Bi}(2)-\mathrm{S}(3)$ & $3.2605(9)$ & $C(14)-C(15)$ & $1.398(4)$ \\
\hline $\mathrm{Bi}(2)-\mathrm{S}(2)$ & $3.6201(10)$ & $C(14)-S(2)$ & $1.774(3)$ \\
\hline $\mathrm{C}(1)-\mathrm{N}(1)$ & $1.375(4)$ & $C(15)-C(16)$ & $1.394(4)$ \\
\hline$C(1)-C(10) \# 1$ & $1.403(4)$ & $C(15)-S(3)$ & $1.764(3)$ \\
\hline$C(1)-C(2)$ & $1.440(4)$ & $\mathrm{C}(16)-\mathrm{H}(16)$ & 0.9500 \\
\hline$C(2)-C(3)$ & $1.345(4)$ & $C(17)-S(1)$ & $1.804(4)$ \\
\hline $\mathrm{C}(2)-\mathrm{H}(2)$ & 0.9500 & $\mathrm{C}(17)-\mathrm{H}(17 \mathrm{~A})$ & 0.9800 \\
\hline$C(3)-C(4)$ & $1.443(4)$ & $\mathrm{C}(17)-\mathrm{H}(17 \mathrm{~B})$ & 0.9800 \\
\hline $\mathrm{C}(3)-\mathrm{H}(3)$ & 0.9500 & $\mathrm{C}(17)-\mathrm{H}(17 \mathrm{C})$ & 0.9800 \\
\hline
\end{tabular}




\begin{tabular}{|c|c|}
\hline$C(18)-S(2)$ & $1.810(4)$ \\
\hline $\mathrm{C}(18)-\mathrm{H}(18 \mathrm{~A})$ & 0.9800 \\
\hline $\mathrm{C}(18)-\mathrm{H}(18 \mathrm{~B})$ & 0.9800 \\
\hline $\mathrm{C}(18)-\mathrm{H}(18 \mathrm{C})$ & 0.9800 \\
\hline$C(19)-S(3)$ & $1.797(4)$ \\
\hline $\mathrm{C}(19)-\mathrm{H}(19 \mathrm{~A})$ & 0.9800 \\
\hline $\mathrm{C}(19)-\mathrm{H}(19 \mathrm{~B})$ & 0.9800 \\
\hline $\mathrm{C}(19)-\mathrm{H}(19 \mathrm{C})$ & 0.9800 \\
\hline$C(20)-C(25)$ & $1.396(4)$ \\
\hline$C(20)-C(21)$ & $1.397(4)$ \\
\hline$C(21)-C(22)$ & $1.401(4)$ \\
\hline $\mathrm{C}(21)-\mathrm{H}(21)$ & 0.9500 \\
\hline$C(22)-C(23)$ & $1.396(5)$ \\
\hline$C(22)-S(4)$ & $1.765(3)$ \\
\hline$C(23)-C(24)$ & $1.406(4)$ \\
\hline$C(23)-S(5)$ & $1.777(3)$ \\
\hline$C(24)-C(25)$ & $1.395(4)$ \\
\hline$C(24)-S(6)$ & $1.763(3)$ \\
\hline $\mathrm{C}(25)-\mathrm{H}(25)$ & 0.9500 \\
\hline$C(26)-S(4)$ & $1.802(4)$ \\
\hline $\mathrm{C}(26)-\mathrm{H}(26 \mathrm{~A})$ & 0.9800 \\
\hline $\mathrm{C}(26)-\mathrm{H}(26 \mathrm{~B})$ & 0.9800 \\
\hline $\mathrm{C}(26)-\mathrm{H}(26 \mathrm{C})$ & 0.9800 \\
\hline$C(27)-S(5)$ & $1.816(3)$ \\
\hline $\mathrm{C}(27)-\mathrm{H}(27 \mathrm{~A})$ & 0.9800 \\
\hline $\mathrm{C}(27)-\mathrm{H}(27 \mathrm{~B})$ & 0.9800 \\
\hline $\mathrm{C}(27)-\mathrm{H}(27 \mathrm{C})$ & 0.9800 \\
\hline$C(28)-S(6)$ & $1.803(3)$ \\
\hline $\mathrm{C}(28)-\mathrm{H}(28 \mathrm{~A})$ & 0.9800 \\
\hline $\mathrm{C}(28)-\mathrm{H}(28 \mathrm{~B})$ & 0.9800 \\
\hline $\mathrm{C}(28)-\mathrm{H}(28 \mathrm{C})$ & 0.9800 \\
\hline$N(3)-O(1)$ & $1.220(10)$ \\
\hline $\mathrm{N}(3)-\mathrm{O}(2)$ & $1.221(6)$ \\
\hline $\mathrm{N}(3)-\mathrm{C}(29)$ & $1.442(6)$ \\
\hline$C(29)-C(30)$ & 1.3900 \\
\hline$C(29)-C(34)$ & 1.3900 \\
\hline$C(30)-C(31)$ & 1.3900 \\
\hline $\mathrm{C}(30)-\mathrm{H}(30)$ & 0.9500 \\
\hline$C(31)-C(32)$ & 1.3900 \\
\hline $\mathrm{C}(31)-\mathrm{H}(31)$ & 0.9500 \\
\hline$C(32)-C(33)$ & 1.3900 \\
\hline $\mathrm{C}(32)-\mathrm{H}(32)$ & 0.9500 \\
\hline$C(33)-C(34)$ & 1.3900 \\
\hline $\mathrm{C}(33)-\mathrm{H}(33)$ & 0.9500 \\
\hline $\mathrm{C}(34)-\mathrm{H}(34)$ & 0.9500 \\
\hline$N(3 B)-O(2 B)$ & $1.218(16)$ \\
\hline$N(3 B)-O(1 B)$ & $1.221(13)$ \\
\hline$N(3 B)-C(29 B)$ & $1.441(12)$ \\
\hline$C(29 B)-C(30 B)$ & 1.3900 \\
\hline$C(29 B)-C(34 B)$ & 1.3900 \\
\hline$C(30 B)-C(31 B)$ & 1.3900 \\
\hline $\mathrm{C}(30 \mathrm{~B})-\mathrm{H}(30 \mathrm{~B})$ & 0.9500 \\
\hline$C(31 B)-C(32 B)$ & 1.3900 \\
\hline $\mathrm{C}(31 \mathrm{~B})-\mathrm{H}(31 \mathrm{~B})$ & 0.9500 \\
\hline$C(32 B)-C(33 B)$ & 1.3900 \\
\hline $\mathrm{C}(32 \mathrm{~B})-\mathrm{H}(32 \mathrm{~B})$ & 0.9500 \\
\hline$C(33 B)-C(34 B)$ & 1.3900 \\
\hline$C(33 B)-H(33 B)$ & 0.9500 \\
\hline $\mathrm{C}(34 \mathrm{~B})-\mathrm{H}(34 \mathrm{~B})$ & 0.9500 \\
\hline$C(35)-C(36)$ & $1.380(5)$ \\
\hline$C(35)-C(40)$ & $1.386(5)$ \\
\hline
\end{tabular}

\begin{tabular}{|c|c|}
\hline $\mathrm{C}(35)-\mathrm{N}(4)$ & $1.460(5)$ \\
\hline$C(36)-C(37)$ & $1.383(5)$ \\
\hline $\mathrm{C}(36)-\mathrm{H}(36)$ & 0.9500 \\
\hline$C(37)-C(38)$ & $1.386(5)$ \\
\hline $\mathrm{C}(37)-\mathrm{H}(37)$ & 0.9500 \\
\hline$C(38)-C(39)$ & $1.373(6)$ \\
\hline $\mathrm{C}(38)-\mathrm{H}(38)$ & 0.9500 \\
\hline$C(39)-C(40)$ & $1.381(6)$ \\
\hline $\mathrm{C}(39)-\mathrm{H}(39)$ & 0.9500 \\
\hline $\mathrm{C}(40)-\mathrm{H}(40)$ & 0.9500 \\
\hline $\mathrm{N}(4)-\mathrm{O}(3)$ & $1.228(4)$ \\
\hline $\mathrm{N}(4)-\mathrm{O}(4)$ & $1.236(4)$ \\
\hline$C(41)-C(46)$ & $1.356(8)$ \\
\hline$C(41)-C(42)$ & $1.362(7)$ \\
\hline $\mathrm{C}(41)-\mathrm{H}(41)$ & 0.9500 \\
\hline$C(42)-C(43)$ & $1.349(9)$ \\
\hline $\mathrm{C}(42)-\mathrm{H}(42)$ & 0.9500 \\
\hline$C(43)-C(44)$ & $1.321(10)$ \\
\hline $\mathrm{C}(43)-\mathrm{H}(43)$ & 0.9500 \\
\hline$C(44)-C(45)$ & $1.360(10)$ \\
\hline $\mathrm{C}(44)-\mathrm{H}(44)$ & 0.9500 \\
\hline$C(45)-C(46)$ & $1.388(10)$ \\
\hline $\mathrm{C}(45)-\mathrm{H}(45)$ & 0.9500 \\
\hline $\mathrm{C}(46)-\mathrm{H}(46)$ & 0.9500 \\
\hline$C(47)-C(52)$ & $1.374(6)$ \\
\hline$C(47)-C(48)$ & $1.375(6)$ \\
\hline $\mathrm{C}(47)-\mathrm{H}(47)$ & 0.9500 \\
\hline$C(48)-C(49)$ & $1.386(5)$ \\
\hline $\mathrm{C}(48)-\mathrm{H}(48)$ & 0.9500 \\
\hline$C(49)-C(50)$ & $1.384(6)$ \\
\hline $\mathrm{C}(49)-\mathrm{H}(49)$ & 0.9500 \\
\hline$C(50)-C(51)$ & $1.373(6)$ \\
\hline $\mathrm{C}(50)-\mathrm{H}(50)$ & 0.9500 \\
\hline$C(51)-C(52)$ & $1.382(6)$ \\
\hline $\mathrm{C}(51)-\mathrm{H}(51)$ & 0.9500 \\
\hline $\mathrm{C}(52)-\mathrm{H}(52)$ & 0.9500 \\
\hline $\mathrm{N}(1)-\mathrm{Cu}(1)$ & $1.994(2)$ \\
\hline $\mathrm{N}(2)-\mathrm{Cu}(1)$ & $2.007(2)$ \\
\hline $\mathrm{Cu}(1)-\mathrm{N}(1) \# 1$ & $1.994(2)$ \\
\hline $\mathrm{Cu}(1)-\mathrm{N}(2) \# 1$ & $2.007(2)$ \\
\hline
\end{tabular}

$\mathrm{Br}(3)-\mathrm{Bi}(1)-\mathrm{Br}(2)$

$\mathrm{Br}(3)-\mathrm{Bi}(1)-\mathrm{Br}(1)$

$\mathrm{Br}(2)-\mathrm{Bi}(1)-\mathrm{Br}(1)$

$\mathrm{Br}(3)-\mathrm{Bi}(1)-\mathrm{S}(1)$

$\mathrm{Br}(2)-\mathrm{Bi}(1)-\mathrm{S}(1)$

$\mathrm{Br}(1)-\mathrm{Bi}(1)-\mathrm{S}(1)$

$\mathrm{Br}(3)-\mathrm{Bi}(1)-\mathrm{S}(2)$

$\mathrm{Br}(2)-\mathrm{Bi}(1)-\mathrm{S}(2)$

$\mathrm{Br}(1)-\mathrm{Bi}(1)-\mathrm{S}(2)$

$\mathrm{S}(1)-\mathrm{Bi}(1)-\mathrm{S}(2)$

$\mathrm{Br}(4)-\mathrm{Bi}(2)-\mathrm{Br}(6)$

$\mathrm{Br}(4)-\mathrm{Bi}(2)-\mathrm{Br}(5)$

$\mathrm{Br}(6)-\mathrm{Bi}(2)-\mathrm{Br}(5)$

$\mathrm{Br}(4)-\mathrm{Bi}(2)-\mathrm{O}(4)$

$\mathrm{Br}(6)-\mathrm{Bi}(2)-\mathrm{O}(4)$

$\mathrm{Br}(5)-\mathrm{Bi}(2)-\mathrm{O}(4)$

$\mathrm{Br}(4)-\mathrm{Bi}(2)-\mathrm{O}(3)$

$\mathrm{Br}(6)-\mathrm{Bi}(2)-\mathrm{O}(3)$

$\mathrm{Br}(5)-\mathrm{Bi}(2)-\mathrm{O}(3)$

$\mathrm{O}(4)-\mathrm{Bi}(2)-\mathrm{O}(3)$
$94.284(14)$
$92.643(15)$
$93.507(15)$
$85.102(19)$
$78.482(19)$
$171.465(18)$
$116.632(17)$
$117.263(19)$
$133.688(16)$
$54.08(2)$
$94.494(16)$
$91.857(13)$
$91.932(12)$
$72.11(5)$
$80.05(6)$
$161.26(5)$
$75.12(5)$
$120.56(5)$
$145.35(5)$
$40.73(8)$ 


\begin{tabular}{|c|c|}
\hline $\mathrm{Br}(4)-\mathrm{Bi}(2)-\mathrm{S}(3)$ & $80.72(2)$ \\
\hline $\mathrm{Br}(6)-\mathrm{Bi}(2)-\mathrm{S}(3)$ & $174.971(18)$ \\
\hline $\mathrm{Br}(5)-\mathrm{Bi}(2)-\mathrm{S}(3)$ & $89.792(17)$ \\
\hline$O(4)-B i(2)-S(3)$ & $96.90(6)$ \\
\hline $\mathrm{O}(3)-\mathrm{Bi}(2)-\mathrm{S}(3)$ & $56.83(6)$ \\
\hline $\mathrm{Br}(4)-\mathrm{Bi}(2)-\mathrm{S}(2)$ & $127.660(16)$ \\
\hline $\mathrm{Br}(6)-\mathrm{Bi}(2)-\mathrm{S}(2)$ & $132.253(17)$ \\
\hline $\mathrm{Br}(5)-\mathrm{Bi}(2)-\mathrm{S}(2)$ & $68.329(16)$ \\
\hline $\mathrm{O}(4)-\mathrm{Bi}(2)-\mathrm{S}(2)$ & $129.17(6)$ \\
\hline$O(3)-B i(2)-S(2)$ & $94.16(6)$ \\
\hline$S(3)-B i(2)-S(2)$ & $52.73(2)$ \\
\hline$N(1)-C(1)-C(10) \# 1$ & $125.5(3)$ \\
\hline$N(1)-C(1)-C(2)$ & $110.8(3)$ \\
\hline$C(10) \# 1-C(1)-C(2)$ & $123.7(3)$ \\
\hline$C(3)-C(2)-C(1)$ & $106.9(3)$ \\
\hline $\mathrm{C}(3)-\mathrm{C}(2)-\mathrm{H}(2)$ & 126.6 \\
\hline $\mathrm{C}(1)-\mathrm{C}(2)-\mathrm{H}(2)$ & 126.6 \\
\hline$C(2)-C(3)-C(4)$ & $107.2(3)$ \\
\hline $\mathrm{C}(2)-\mathrm{C}(3)-\mathrm{H}(3)$ & 126.4 \\
\hline $\mathrm{C}(4)-\mathrm{C}(3)-\mathrm{H}(3)$ & 126.4 \\
\hline$N(1)-C(4)-C(5)$ & $125.2(3)$ \\
\hline$N(1)-C(4)-C(3)$ & $110.1(3)$ \\
\hline$C(5)-C(4)-C(3)$ & $124.5(3)$ \\
\hline$C(6)-C(5)-C(4)$ & $124.9(3)$ \\
\hline$C(6)-C(5)-C(11)$ & $116.4(3)$ \\
\hline$C(4)-C(5)-C(11)$ & $118.7(3)$ \\
\hline$N(2)-C(6)-C(5)$ & $125.7(3)$ \\
\hline$N(2)-C(6)-C(7)$ & $110.2(3)$ \\
\hline$C(5)-C(6)-C(7)$ & $124.1(3)$ \\
\hline$C(8)-C(7)-C(6)$ & $107.2(3)$ \\
\hline $\mathrm{C}(8)-\mathrm{C}(7)-\mathrm{H}(7)$ & 126.4 \\
\hline $\mathrm{C}(6)-\mathrm{C}(7)-\mathrm{H}(7)$ & 126.4 \\
\hline$C(7)-C(8)-C(9)$ & $107.2(3)$ \\
\hline $\mathrm{C}(7)-\mathrm{C}(8)-\mathrm{H}(8)$ & 126.4 \\
\hline $\mathrm{C}(9)-\mathrm{C}(8)-\mathrm{H}(8)$ & 126.4 \\
\hline$N(2)-C(9)-C(10)$ & $125.7(3)$ \\
\hline$N(2)-C(9)-C(8)$ & $109.8(3)$ \\
\hline$C(10)-C(9)-C(8)$ & $124.5(3)$ \\
\hline$C(9)-C(10)-C(1) \# 1$ & $123.6(3)$ \\
\hline$C(9)-C(10)-C(20)$ & $117.5(3)$ \\
\hline$C(1) \# 1-C(10)-C(20)$ & $118.8(3)$ \\
\hline$C(16)-C(11)-C(12)$ & $120.3(3)$ \\
\hline$C(16)-C(11)-C(5)$ & $121.5(3)$ \\
\hline$C(12)-C(11)-C(5)$ & $118.2(3)$ \\
\hline$C(13)-C(12)-C(11)$ & $120.1(3)$ \\
\hline $\mathrm{C}(13)-\mathrm{C}(12)-\mathrm{H}(12)$ & 120.0 \\
\hline $\mathrm{C}(11)-\mathrm{C}(12)-\mathrm{H}(12)$ & 120.0 \\
\hline$C(12)-C(13)-C(14)$ & $119.6(3)$ \\
\hline$C(12)-C(13)-S(1)$ & $123.0(2)$ \\
\hline$C(14)-C(13)-S(1)$ & $117.4(2)$ \\
\hline$C(13)-C(14)-C(15)$ & $120.5(3)$ \\
\hline$C(13)-C(14)-S(2)$ & $119.8(2)$ \\
\hline$C(15)-C(14)-S(2)$ & $119.7(2)$ \\
\hline$C(16)-C(15)-C(14)$ & $119.4(3)$ \\
\hline$C(16)-C(15)-S(3)$ & $123.8(2)$ \\
\hline$C(14)-C(15)-S(3)$ & $116.8(2)$ \\
\hline$C(11)-C(16)-C(15)$ & $120.1(3)$ \\
\hline $\mathrm{C}(11)-\mathrm{C}(16)-\mathrm{H}(16)$ & 120.0 \\
\hline $\mathrm{C}(15)-\mathrm{C}(16)-\mathrm{H}(16)$ & 120.0 \\
\hline$S(1)-C(17)-H(17 A)$ & 109.5 \\
\hline $\mathrm{S}(1)-\mathrm{C}(17)-\mathrm{H}(17 \mathrm{~B})$ & \\
\hline
\end{tabular}

$\mathrm{Br}(4)-\mathrm{Bi}(2)-\mathrm{S}(3)$

$O(4)-B i(2)-S(3)$

$\mathrm{O}(3)-\mathrm{Bi}(2)-\mathrm{S}(3)$

$\mathrm{Br}(4)-\mathrm{Bi}(2)-\mathrm{S}(2)$

$\mathrm{Br}(6)-\mathrm{Bi}(2)-\mathrm{S}(2)$

$\mathrm{Br}(5)-\mathrm{Bi}(2)-\mathrm{S}(2)$

$S(3)-B i(2)-S(2)$

$\mathrm{N}(1)-\mathrm{C}(1)-\mathrm{C}(10) \# 1$

$\mathrm{N}(1)-\mathrm{C}(1)-\mathrm{C}(2)$

$C(10) \# 1-C(1)-C(2)$

$C(3)-C(2)-C(1)$

$\mathrm{C}(3)-\mathrm{C}(2)-\mathrm{H}(2)$

$\mathrm{C}(1)-\mathrm{C}(2)-\mathrm{H}(2)$

$C(2)-C(3)-C(4)$

(2) $-\mathrm{C}(3)-\mathrm{H}(3)$

$\mathrm{N}(1)-\mathrm{C}(4)-\mathrm{C}(5)$

$\mathrm{N}(1)-\mathrm{C}(4)-\mathrm{C}(3)$

$C(5)-C(4)-C(3)$

$C(6)-C(5)-C(11)$

$C(4)-C(5)-C(11)$

$\mathrm{N}(2)-\mathrm{C}(6)-\mathrm{C}(5)$

$\mathrm{N}(2)-\mathrm{C}(6)-\mathrm{C}(7)$

$-C(6)-C(7)$

$\mathrm{C}(8)-\mathrm{C}(7)-\mathrm{H}(7)$

$\mathrm{C}(6)-\mathrm{C}(7)-\mathrm{H}(7)$

$C(7)-C(8)-C(9)$

$\mathrm{N}(2)-\mathrm{C}(9)-\mathrm{C}(10)$

$\mathrm{N}(2)-\mathrm{C}(9)-\mathrm{C}(8)$

$C(10)-C(9)-C(8)$

$C(9)-C(10)-C(20)$

$C(1) \# 1-C(10)-C(20)$

$C(12)-C(11)-C(5)$

$C(13)-C(12)-C(11)$

$\mathrm{C}(13)-\mathrm{C}(12)-\mathrm{H}(12)$

$C(12)-C(13)-S(1)$

$C(14)-C(13)-S(1)$

$C(13)-C(14)-C(15)$

$C(16)-C(15)-C(14)$

$C(16)-C(15)-S(3)$

$C(14)-C(15)-S(3)$

$\mathrm{C}(11)-\mathrm{C}(16)-\mathrm{H}(16)$

$\mathrm{S}(1)-\mathrm{C}(17)-\mathrm{H}(17 \mathrm{~A})$

$S(1)-C(17)-H(17 B)$
$\mathrm{H}(17 \mathrm{~A})-\mathrm{C}(17)-\mathrm{H}(17 \mathrm{~B})$

109.5

$\mathrm{S}(1)-\mathrm{C}(17)-\mathrm{H}(17 \mathrm{C})$

$\mathrm{H}(17 \mathrm{~A})-\mathrm{C}(17)-\mathrm{H}(17 \mathrm{C})$

$\mathrm{H}(17 \mathrm{~B})-\mathrm{C}(17)-\mathrm{H}(17 \mathrm{C})$

$\mathrm{S}(2)-\mathrm{C}(18)-\mathrm{H}(18 \mathrm{~A})$

$\mathrm{S}(2)-\mathrm{C}(18)-\mathrm{H}(18 \mathrm{~B})$

$\mathrm{H}(18 \mathrm{~A})-\mathrm{C}(18)-\mathrm{H}(18 \mathrm{~B})$

$\mathrm{S}(2)-\mathrm{C}(18)-\mathrm{H}(18 \mathrm{C})$

$\mathrm{H}(18 \mathrm{~A})-\mathrm{C}(18)-\mathrm{H}(18 \mathrm{C})$

$\mathrm{H}(18 \mathrm{~B})-\mathrm{C}(18)-\mathrm{H}(18 \mathrm{C})$

$\mathrm{S}(3)-\mathrm{C}(19)-\mathrm{H}(19 \mathrm{~A})$

$S(3)-C(19)-H(19 B)$

$\mathrm{H}(19 \mathrm{~A})-\mathrm{C}(19)-\mathrm{H}$ (19B)

$\mathrm{S}(3)-\mathrm{C}(19)-\mathrm{H}(19 \mathrm{C})$

$\mathrm{H}(19 \mathrm{~A})-\mathrm{C}(19)-\mathrm{H}(19 \mathrm{C})$

$\mathrm{H}(19 \mathrm{~B})-\mathrm{C}(19)-\mathrm{H}(19 \mathrm{C})$

$C(25)-C(20)-C(21)$

$C(25)-C(20)-C(10)$

$C(21)-C(20)-C(10)$

$C(20)-C(21)-C(22)$

$\mathrm{C}(20)-\mathrm{C}(21)-\mathrm{H}(21)$

$\mathrm{C}(22)-\mathrm{C}(21)-\mathrm{H}(21)$

$\mathrm{C}(23)-\mathrm{C}(22)-\mathrm{C}(21)$

$C(23)-C(22)-S(4)$

$\mathrm{C}(21)-\mathrm{C}(22)-\mathrm{S}(4)$

$C(22)-C(23)-C(24)$

$C(22)-C(23)-S(5)$

$C(24)-C(23)-S(5)$

$C(25)-C(24)-C(23)$

$C(25)-C(24)-S(6)$

$C(23)-C(24)-S(6)$

$\mathrm{C}(24)-\mathrm{C}(25)-\mathrm{C}(20)$

$\mathrm{C}(24)-\mathrm{C}(25)-\mathrm{H}(25)$

$\mathrm{C}(20)-\mathrm{C}(25)-\mathrm{H}(25)$

$\mathrm{S}(4)-\mathrm{C}(26)-\mathrm{H}(26 \mathrm{~A})$

$\mathrm{S}(4)-\mathrm{C}(26)-\mathrm{H}(26 \mathrm{~B})$

$\mathrm{H}(26 \mathrm{~A})-\mathrm{C}(26)-\mathrm{H}(26 \mathrm{~B})$

$\mathrm{S}(4)-\mathrm{C}(26)-\mathrm{H}(26 \mathrm{C})$

$\mathrm{H}(26 \mathrm{~A})-\mathrm{C}(26)-\mathrm{H}(26 \mathrm{C})$

$\mathrm{H}(26 \mathrm{~B})-\mathrm{C}(26)-\mathrm{H}(26 \mathrm{C})$

$S(5)-C(27)-H(27 A)$

$\mathrm{S}(5)-\mathrm{C}(27)-\mathrm{H}(27 \mathrm{~B})$

$\mathrm{H}(27 \mathrm{~A})-\mathrm{C}(27)-\mathrm{H}(27 \mathrm{~B})$

$\mathrm{S}(5)-\mathrm{C}(27)-\mathrm{H}(27 \mathrm{C})$

$\mathrm{H}(27 \mathrm{~A})-\mathrm{C}(27)-\mathrm{H}(27 \mathrm{C})$

$\mathrm{H}(27 \mathrm{~B})-\mathrm{C}(27)-\mathrm{H}(27 \mathrm{C})$

$S(6)-C(28)-H(28 A)$

$\mathrm{S}(6)-\mathrm{C}(28)-\mathrm{H}(28 \mathrm{~B})$

$\mathrm{H}(28 \mathrm{~A})-\mathrm{C}(28)-\mathrm{H}(28 \mathrm{~B})$

$\mathrm{S}(6)-\mathrm{C}(28)-\mathrm{H}(28 \mathrm{C})$

$\mathrm{H}(28 \mathrm{~A})-\mathrm{C}(28)-\mathrm{H}(28 \mathrm{C})$

$\mathrm{H}(28 \mathrm{~B})-\mathrm{C}(28)-\mathrm{H}(28 \mathrm{C})$

$\mathrm{O}(1)-\mathrm{N}(3)-\mathrm{O}(2)$

$\mathrm{O}(1)-\mathrm{N}(3)-\mathrm{C}(29)$

$\mathrm{O}(2)-\mathrm{N}(3)-\mathrm{C}(29)$

$\mathrm{C}(30)-\mathrm{C}(29)-\mathrm{C}(34)$

$\mathrm{C}(30)-\mathrm{C}(29)-\mathrm{N}(3)$

$\mathrm{C}(34)-\mathrm{C}(29)-\mathrm{N}(3)$

$C(31)-C(30)-C(29)$

$\mathrm{C}(31)-\mathrm{C}(30)-\mathrm{H}(30)$

$\mathrm{C}(29)-\mathrm{C}(30)-\mathrm{H}(30)$

109.5
109.5

109.5

109.5

109.5

109.5

109.5

109.5

109.5

109.5

109.5

109.5

109.5

109.5

109.5

$119.6(3)$

$121.2(3)$

$119.1(3)$

$120.6(3)$

119.7

119.7

$119.3(3)$

$118.2(2)$

$122.5(2)$

$120.5(3)$

$119.8(2)$

$119.5(2)$

$119.3(3)$

$123.8(2)$

$116.8(2)$

$120.6(3)$

119.7

119.7

109.5

109.5

109.5

109.5

109.5

109.5

109.5

109.5

109.5

109.5

109.5

109.5

109.5

109.5

109.5

109.5

109.5

109.5

$124.2(7)$

$118.5(7)$

$117.3(5)$

120.0

$119.8(4)$

$120.2(4)$

120.0

120.0

120.0 


\begin{tabular}{|c|c|}
\hline$C(30)-C(31)-C(32)$ & 120.0 \\
\hline $\mathrm{C}(30)-\mathrm{C}(31)-\mathrm{H}(31)$ & 120.0 \\
\hline $\mathrm{C}(32)-\mathrm{C}(31)-\mathrm{H}(31)$ & 120.0 \\
\hline$C(33)-C(32)-C(31)$ & 120.0 \\
\hline $\mathrm{C}(33)-\mathrm{C}(32)-\mathrm{H}(32)$ & 120.0 \\
\hline $\mathrm{C}(31)-\mathrm{C}(32)-\mathrm{H}(32)$ & 120.0 \\
\hline$C(32)-C(33)-C(34)$ & 120.0 \\
\hline $\mathrm{C}(32)-\mathrm{C}(33)-\mathrm{H}(33)$ & 120.0 \\
\hline $\mathrm{C}(34)-\mathrm{C}(33)-\mathrm{H}(33)$ & 120.0 \\
\hline$C(33)-C(34)-C(29)$ & 120.0 \\
\hline $\mathrm{C}(33)-\mathrm{C}(34)-\mathrm{H}(34)$ & 120.0 \\
\hline $\mathrm{C}(29)-\mathrm{C}(34)-\mathrm{H}(34)$ & 120.0 \\
\hline$O(2 B)-N(3 B)-O(1 B)$ & $122.8(15)$ \\
\hline$O(2 B)-N(3 B)-C(29 B)$ & $122.4(14)$ \\
\hline $\mathrm{O}(1 \mathrm{~B})-\mathrm{N}(3 \mathrm{~B})-\mathrm{C}(29 \mathrm{~B})$ & $114.8(14)$ \\
\hline$C(30 B)-C(29 B)-C(34 B)$ & 120.0 \\
\hline$C(30 B)-C(29 B)-N(3 B)$ & $123.7(10)$ \\
\hline$C(34 B)-C(29 B)-N(3 B)$ & $116.2(10)$ \\
\hline$C(29 B)-C(30 B)-C(31 B)$ & 120.0 \\
\hline$C(29 B)-C(30 B)-H(30 B)$ & 120.0 \\
\hline$C(31 B)-C(30 B)-H(30 B)$ & 120.0 \\
\hline$C(32 B)-C(31 B)-C(30 B)$ & 120.0 \\
\hline$C(32 B)-C(31 B)-H(31 B)$ & 120.0 \\
\hline$C(30 B)-C(31 B)-H(31 B)$ & 120.0 \\
\hline$C(31 B)-C(32 B)-C(33 B)$ & 120.0 \\
\hline$C(31 B)-C(32 B)-H(32 B)$ & 120.0 \\
\hline$C(33 B)-C(32 B)-H(32 B)$ & 120.0 \\
\hline$C(34 B)-C(33 B)-C(32 B)$ & 120.0 \\
\hline$C(34 B)-C(33 B)-H(33 B)$ & 120.0 \\
\hline$C(32 B)-C(33 B)-H(33 B)$ & 120.0 \\
\hline$C(33 B)-C(34 B)-C(29 B)$ & 120.0 \\
\hline$C(33 B)-C(34 B)-H(34 B)$ & 120.0 \\
\hline$C(29 B)-C(34 B)-H(34 B)$ & 120.0 \\
\hline$C(36)-C(35)-C(40)$ & $123.0(3)$ \\
\hline$C(36)-C(35)-N(4)$ & $118.4(3)$ \\
\hline$C(40)-C(35)-N(4)$ & $118.6(3)$ \\
\hline$C(35)-C(36)-C(37)$ & $117.8(3)$ \\
\hline $\mathrm{C}(35)-\mathrm{C}(36)-\mathrm{H}(36)$ & 121.1 \\
\hline $\mathrm{C}(37)-\mathrm{C}(36)-\mathrm{H}(36)$ & 121.1 \\
\hline$C(36)-C(37)-C(38)$ & $120.3(3)$ \\
\hline $\mathrm{C}(36)-\mathrm{C}(37)-\mathrm{H}(37)$ & 119.8 \\
\hline $\mathrm{C}(38)-\mathrm{C}(37)-\mathrm{H}(37)$ & 119.8 \\
\hline$C(39)-C(38)-C(37)$ & $120.5(4)$ \\
\hline $\mathrm{C}(39)-\mathrm{C}(38)-\mathrm{H}(38)$ & 119.7 \\
\hline $\mathrm{C}(37)-\mathrm{C}(38)-\mathrm{H}(38)$ & 119.7 \\
\hline$C(38)-C(39)-C(40)$ & $120.6(4)$ \\
\hline $\mathrm{C}(38)-\mathrm{C}(39)-\mathrm{H}(39)$ & 119.7 \\
\hline $\mathrm{C}(40)-\mathrm{C}(39)-\mathrm{H}(39)$ & 119.7 \\
\hline$C(39)-C(40)-C(35)$ & $117.8(4)$ \\
\hline $\mathrm{C}(39)-\mathrm{C}(40)-\mathrm{H}(40)$ & 121.1 \\
\hline $\mathrm{C}(35)-\mathrm{C}(40)-\mathrm{H}(40)$ & 121.1 \\
\hline $\mathrm{O}(3)-\mathrm{N}(4)-\mathrm{O}(4)$ & $122.3(3)$ \\
\hline$O(3)-N(4)-C(35)$ & $119.0(3)$ \\
\hline$O(4)-N(4)-C(35)$ & $118.7(3)$ \\
\hline $\mathrm{N}(4)-\mathrm{O}(3)-\mathrm{Bi}(2)$ & $94.9(2)$ \\
\hline $\mathrm{N}(4)-\mathrm{O}(4)-\mathrm{Bi}(2)$ & $96.7(2)$ \\
\hline$C(46)-C(41)-C(42)$ & $120.0(5)$ \\
\hline $\mathrm{C}(46)-\mathrm{C}(41)-\mathrm{H}(41)$ & 120.0 \\
\hline $\mathrm{C}(42)-\mathrm{C}(41)-\mathrm{H}(41)$ & 120.0 \\
\hline$C(43)-C(42)-C(41)$ & $120.1(6)$ \\
\hline $\mathrm{C}(43)-\mathrm{C}(42)-\mathrm{H}(42)$ & 120.0 \\
\hline
\end{tabular}

$\mathrm{C}(41)-\mathrm{C}(42)-\mathrm{H}(42) \quad 120.0$

$C(44)-C(43)-C(42)$

$\mathrm{C}(44)-\mathrm{C}(43)-\mathrm{H}(43)$

$\mathrm{C}(42)-\mathrm{C}(43)-\mathrm{H}(43)$

$\mathrm{C}(43)-\mathrm{C}(44)-\mathrm{C}(45)$

$\mathrm{C}(43)-\mathrm{C}(44)-\mathrm{H}(44)$

$\mathrm{C}(45)-\mathrm{C}(44)-\mathrm{H}(44)$

$C(44)-C(45)-C(46)$

$\mathrm{C}(44)-\mathrm{C}(45)-\mathrm{H}(45)$

$\mathrm{C}(46)-\mathrm{C}(45)-\mathrm{H}(45)$

$C(41)-C(46)-C(45)$

$\mathrm{C}(41)-\mathrm{C}(46)-\mathrm{H}(46)$

$\mathrm{C}(45)-\mathrm{C}(46)-\mathrm{H}(46)$

$C(52)-C(47)-C(48)$

$\mathrm{C}(52)-\mathrm{C}(47)-\mathrm{H}(47)$

$\mathrm{C}(48)-\mathrm{C}(47)-\mathrm{H}(47)$

$C(47)-C(48)-C(49)$

$\mathrm{C}(47)-\mathrm{C}(48)-\mathrm{H}(48)$

$\mathrm{C}(49)-\mathrm{C}(48)-\mathrm{H}(48)$

$C(50)-C(49)-C(48)$

$\mathrm{C}(50)-\mathrm{C}(49)-\mathrm{H}(49)$

$\mathrm{C}(48)-\mathrm{C}(49)-\mathrm{H}(49)$

$C(51)-C(50)-C(49)$

$\mathrm{C}(51)-\mathrm{C}(50)-\mathrm{H}(50)$

$\mathrm{C}(49)-\mathrm{C}(50)-\mathrm{H}(50)$

$C(50)-C(51)-C(52)$

$\mathrm{C}(50)-\mathrm{C}(51)-\mathrm{H}(51)$

$\mathrm{C}(52)-\mathrm{C}(51)-\mathrm{H}(51)$

C (47) - C (52)-C (51)

$\mathrm{C}(47)-\mathrm{C}(52)-\mathrm{H}(52)$

$\mathrm{C}(51)-\mathrm{C}(52)-\mathrm{H}(52)$

$\mathrm{C}(1)-\mathrm{N}(1)-\mathrm{C}(4)$

$\mathrm{C}(1)-\mathrm{N}(1)-\mathrm{Cu}(1)$

$\mathrm{C}(4)-\mathrm{N}(1)-\mathrm{Cu}(1)$

$\mathrm{C}(6)-\mathrm{N}(2)-\mathrm{C}(9)$

$\mathrm{C}(6)-\mathrm{N}(2)-\mathrm{Cu}(1)$

$\mathrm{C}(9)-\mathrm{N}(2)-\mathrm{Cu}(1)$

$\mathrm{C}(13)-\mathrm{S}(1)-\mathrm{C}(17)$

$\mathrm{C}(13)-\mathrm{S}(1)-\mathrm{Bi}(1)$

$\mathrm{C}(17)-\mathrm{S}(1)-\mathrm{Bi}(1)$

$C(14)-S(2)-C(18)$

$C(14)-S(2)-B i(2)$

$\mathrm{C}(18)-\mathrm{S}(2)-\mathrm{Bi}(2)$

$\mathrm{C}(14)-\mathrm{S}(2)-\mathrm{Bi}(1)$

$\mathrm{C}(18)-\mathrm{S}(2)-\mathrm{Bi}(1)$

$\mathrm{Bi}(2)-\mathrm{S}(2)-\mathrm{Bi}(1)$

$C(15)-S(3)-C(19)$

$\mathrm{C}(15)-\mathrm{S}(3)-\mathrm{Bi}(2)$

$\mathrm{C}(19)-\mathrm{S}(3)-\mathrm{Bi}(2)$

$C(22)-S(4)-C(26)$

$C(23)-S(5)-C(27)$

$C(24)-S(6)-C(28)$

$\mathrm{N}(1) \# 1-\mathrm{Cu}(1)-\mathrm{N}(1)$

$\mathrm{N}(1) \# 1-\mathrm{Cu}(1)-\mathrm{N}(2)$

$\mathrm{N}(1)-\mathrm{Cu}(1)-\mathrm{N}(2)$

$\mathrm{N}(1) \# 1-\mathrm{Cu}(1)-\mathrm{N}(2)$ \#1

$\mathrm{N}(1)-\mathrm{Cu}(1)-\mathrm{N}(2) \# 1$

$\mathrm{N}(2)-\mathrm{Cu}(1)-\mathrm{N}(2) \# 1$
$120.7(6)$
119.7
119.7
$121.2(6)$
119.4
119.4
$118.8(5)$
120.6
120.6
$119.2(6)$
120.4
120.4
$120.5(4)$
119.7
119.7
$119.7(4)$
120.1
120.1
$119.7(4)$
120.2
120.2
$120.2(4)$
119.9
119.9
$120.0(4)$
120.0
120.0
$119.8(4)$
120.1
120.1
$104.9(4)$
$128.1(2)$
$127.0(2)$
$105.7(2)$
$126.6(2)$
$127.6(2)$
$103.17(16)$
$104.36(11)$
$107.31(13)$
99.82 
Symmetry transformations used to generate equivalent atoms:

$\# 1-x+1,-y+1,-z+2 \quad \# 2 x-0.5,0.5-y, z-0.5$

Table s9. Anisotropic displacement parameters $\left[\AA^{2} \times 10^{3}\right]$ for 3 . The anisotropic displacement factor exponent takes the form: $-2 \pi 2\left[\left(h a^{*}\right)^{2}\right.$ U11 + $\ldots+2 h k a * b * U 12]$

\begin{tabular}{|c|c|c|c|c|c|c|}
\hline & U11 & U22 & U33 & U23 & U13 & U12 \\
\hline $\mathrm{Bi}(1)$ & $16(1)$ & $16(1)$ & $11(1)$ & $-1(1)$ & $2(1)$ & $-1(1)$ \\
\hline $\mathrm{Bi}(2)$ & $15(1)$ & $17(1)$ & $17(1)$ & $-4(1)$ & $7(1)$ & $-4(1)$ \\
\hline $\operatorname{Br}(1)$ & $21(1)$ & $31(1)$ & $23(1)$ & $0(1)$ & $-3(1)$ & $7(1)$ \\
\hline $\operatorname{Br}(2)$ & $26(1)$ & $28(1)$ & $14(1)$ & $6(1)$ & $4(1)$ & $-2(1)$ \\
\hline $\operatorname{Br}(3)$ & $28(1)$ & $32(1)$ & $21(1)$ & $-14(1)$ & $7(1)$ & $-11(1)$ \\
\hline $\operatorname{Br}(4)$ & $36(1)$ & $28(1)$ & 29 (1) & $-2(1)$ & $16(1)$ & $-16(1)$ \\
\hline $\operatorname{Br}(5)$ & $24(1)$ & 21 (1) & $17(1)$ & $-6(1)$ & $7(1)$ & $-7(1)$ \\
\hline $\operatorname{Br}(6)$ & $13(1)$ & $31(1)$ & $37(1)$ & $-6(1)$ & $10(1)$ & $-2(1)$ \\
\hline$C(1)$ & $11(2)$ & $14(1)$ & $13(2)$ & $-2(1)$ & $0(1)$ & $0(1)$ \\
\hline$C(2)$ & $15(2)$ & $17(2)$ & $17(2)$ & $-3(1)$ & $-5(1)$ & $2(1)$ \\
\hline$C(3)$ & $17(2)$ & $13(1)$ & $18(2)$ & $-4(1)$ & $-2(1)$ & $0(1)$ \\
\hline$C(4)$ & $14(2)$ & $13(1)$ & $12(2)$ & $-3(1)$ & $1(1)$ & $0(1)$ \\
\hline$C(5)$ & $14(2)$ & $11(1)$ & $13(2)$ & $-1(1)$ & $2(1)$ & $0(1)$ \\
\hline$C(6)$ & $12(2)$ & $9(1)$ & $14(2)$ & $1(1)$ & $2(1)$ & $0(1)$ \\
\hline$C(7)$ & $15(2)$ & $10(1)$ & $17(2)$ & $-1(1)$ & $3(1)$ & $2(1)$ \\
\hline$C(8)$ & $14(2)$ & 12 (1) & $16(2)$ & $1(1)$ & $3(1)$ & $4(1)$ \\
\hline C (9) & $11(1)$ & $12(1)$ & $10(1)$ & $1(1)$ & $0(1)$ & $2(1)$ \\
\hline$C(10)$ & $11(2)$ & $13(1)$ & $14(2)$ & $1(1)$ & $1(1)$ & $1(1)$ \\
\hline$C(11)$ & $7(1)$ & $12(1)$ & $15(2)$ & $-1(1)$ & $0(1)$ & $1(1)$ \\
\hline$C(12)$ & $11(2)$ & $14(1)$ & $14(2)$ & $-4(1)$ & $2(1)$ & $1(1)$ \\
\hline$C(13)$ & $14(2)$ & 11 (1) & $13(2)$ & $2(1)$ & $3(1)$ & $2(1)$ \\
\hline$C(14)$ & $15(2)$ & $10(1)$ & $16(2)$ & $-1(1)$ & $2(1)$ & $3(1)$ \\
\hline$C(15)$ & $16(2)$ & $13(1)$ & $12(2)$ & $-3(1)$ & $4(1)$ & $3(1)$ \\
\hline$C(16)$ & $16(2)$ & 12 (1) & $17(2)$ & $4(1)$ & $4(1)$ & $3(1)$ \\
\hline$C(17)$ & $42(2)$ & $24(2)$ & $22(2)$ & $2(1)$ & $18(2)$ & $8(2)$ \\
\hline$C(18)$ & $30(2)$ & $19(2)$ & $35(2)$ & $-10(2)$ & $-1(2)$ & $-2(2)$ \\
\hline C (19) & $60(3)$ & $21(2)$ & $27(2)$ & $8(2)$ & $24(2)$ & $10(2)$ \\
\hline$C(20)$ & $13(2)$ & $8(1)$ & $15(2)$ & $-1(1)$ & $1(1)$ & $-2(1)$ \\
\hline$C(21)$ & $12(2)$ & $12(1)$ & $17(2)$ & $-1(1)$ & $1(1)$ & $2(1)$ \\
\hline$C(22)$ & $14(2)$ & $9(1)$ & $13(2)$ & $-2(1)$ & $0(1)$ & $0(1)$ \\
\hline$C(23)$ & $12(2)$ & $8(1)$ & $16(2)$ & $1(1)$ & $-3(1)$ & $-1(1)$ \\
\hline$C(24)$ & $11(2)$ & $11(1)$ & $16(2)$ & $0(1)$ & $2(1)$ & $0(1)$ \\
\hline$C(25)$ & $13(2)$ & $13(1)$ & $14(2)$ & $-1(1)$ & $0(1)$ & $-2(1)$ \\
\hline$C(26)$ & $19(2)$ & $36(2)$ & $18(2)$ & $-2(2)$ & $7(1)$ & $7(2)$ \\
\hline$C(27)$ & $20(2)$ & $25(2)$ & $24(2)$ & $2(1)$ & $0(2)$ & $-9(1)$ \\
\hline$C(28)$ & $22(2)$ & $30(2)$ & $14(2)$ & $4(1)$ & $3(1)$ & $8(2)$ \\
\hline $\mathrm{N}(3)$ & $43(3)$ & $37(3)$ & $34(3)$ & $14(2)$ & $27(3)$ & $16(3)$ \\
\hline$O(1)$ & 79 ( 8 ) & $30(4)$ & $45(4)$ & $-2(3)$ & $41(4)$ & $5(4)$ \\
\hline $\mathrm{O}(2)$ & $42(3)$ & $56(3)$ & $61(3)$ & $26(3)$ & $20(3)$ & $31(2)$ \\
\hline C (29) & $15(3)$ & $28(3)$ & $14(3)$ & $2(2)$ & $6(3)$ & $0(2)$ \\
\hline$C(30)$ & $31(4)$ & $25(3)$ & $20(3)$ & $5(2)$ & $10(3)$ & $1(3)$ \\
\hline$C(31)$ & $24(3)$ & $23(3)$ & $27(3)$ & $12(2)$ & $8(3)$ & $7(2)$ \\
\hline$C(32)$ & $27(4)$ & $33(3)$ & $32(5)$ & $-1(3)$ & $13(4)$ & $1(3)$ \\
\hline$C(33)$ & $35(6)$ & $25(3)$ & $22(5)$ & $-1(3)$ & $8(5)$ & $-7(4)$ \\
\hline$C(34)$ & $20(3)$ & $42(4)$ & $20(3)$ & $2(3)$ & $5(3)$ & $-8(3)$ \\
\hline$N(3 B)$ & $82(12)$ & $28(7)$ & $39(8)$ & $-13(6)$ & $36(8)$ & $-27(7)$ \\
\hline$O(1 B)$ & $70(9)$ & $74(8)$ & $47(7)$ & $-31(6)$ & $34(6)$ & $-46(7)$ \\
\hline
\end{tabular}




\begin{tabular}{|c|c|c|c|c|c|c|}
\hline $\mathrm{O}(2 \mathrm{~B})$ & $73(17)$ & $37(11)$ & $130(20)$ & $-14(11)$ & $81(15)$ & $0(8)$ \\
\hline$C(29 B)$ & $15(7)$ & $26(7)$ & $12(7)$ & $-3(5)$ & $-6(6)$ & $-1(5)$ \\
\hline$C(30 B)$ & $44(10)$ & $29(9)$ & $32(8)$ & $-1(7)$ & $23(7)$ & $-10(8)$ \\
\hline$C(31 B)$ & $31(10)$ & $24(6)$ & $29(10)$ & $1(6)$ & $22(8)$ & $0(6)$ \\
\hline$C(32 B)$ & $22(12)$ & $35(9)$ & 45 (15) & $-4(9)$ & $14(11)$ & $-7(8)$ \\
\hline$C(33 B)$ & $19(7)$ & $27(7)$ & $34(8)$ & $-19(6)$ & $5(6)$ & $-7(5)$ \\
\hline$C(34 B)$ & $72(13)$ & $22(7)$ & $45(10)$ & $-14(7)$ & $35(10)$ & $-11(8)$ \\
\hline$C(35)$ & $25(2)$ & $17(2)$ & $15(2)$ & $-5(1)$ & $6(1)$ & $-6(1)$ \\
\hline$C(36)$ & $22(2)$ & $21(2)$ & $17(2)$ & $0(1)$ & $4(1)$ & $2(1)$ \\
\hline$C(37)$ & $24(2)$ & $28(2)$ & $19(2)$ & $-3(1)$ & $8(2)$ & $0(2)$ \\
\hline$C(38)$ & $32(2)$ & $21(2)$ & $21(2)$ & $0(1)$ & $4(2)$ & $-1(2)$ \\
\hline$C(39)$ & $34(2)$ & $25(2)$ & $37(2)$ & $3(2)$ & $6(2)$ & $11(2)$ \\
\hline$C(40)$ & $27(2)$ & $31(2)$ & $34(2)$ & $-4(2)$ & $14(2)$ & $7(2)$ \\
\hline $\mathrm{N}(4)$ & $35(2)$ & $31(2)$ & $20(2)$ & $-8(1)$ & $12(2)$ & $-14(2)$ \\
\hline$O(3)$ & $48(2)$ & $40(2)$ & $33(2)$ & $-10(1)$ & $26(1)$ & $-10(1)$ \\
\hline$O(4)$ & $38(2)$ & $40(2)$ & $21(1)$ & $4(1)$ & $6(1)$ & $-8(1)$ \\
\hline$C(41)$ & $60(3)$ & $59(3)$ & $35(3)$ & $-8(2)$ & $10(2)$ & $8(3)$ \\
\hline$C(42)$ & $37(3)$ & $66(4)$ & $88(5)$ & $-27(3)$ & $-4(3)$ & $8(3)$ \\
\hline$C(43)$ & $83(5)$ & $73(4)$ & $100(5)$ & $-47(4)$ & $66(5)$ & $-35(4)$ \\
\hline$C(44)$ & $128(7)$ & $77(5)$ & $34(3)$ & $-10(3)$ & $16(4)$ & $-80(5)$ \\
\hline$C(45)$ & $54(4)$ & $65(4)$ & $88(5)$ & $49(4)$ & $-32(4)$ & $-35(3)$ \\
\hline$C(46)$ & $52(3)$ & $46(3)$ & $103(5)$ & $13(3)$ & $42(4)$ & $8(3)$ \\
\hline$C(47)$ & $34(2)$ & $24(2)$ & $31(2)$ & $5(2)$ & $-1(2)$ & $-2(2)$ \\
\hline$C(48)$ & $28(2)$ & $24(2)$ & $35(2)$ & $-6(2)$ & $4(2)$ & $3(2)$ \\
\hline$C(49)$ & $28(2)$ & $32(2)$ & $26(2)$ & $-5(2)$ & $6(2)$ & $-8(2)$ \\
\hline$C(50)$ & $42(2)$ & $22(2)$ & $22(2)$ & $-4(2)$ & $-3(2)$ & $-2(2)$ \\
\hline$C(51)$ & $37(2)$ & $44(2)$ & $23(2)$ & $-6(2)$ & $5(2)$ & $10(2)$ \\
\hline$C(52)$ & $30(2)$ & $48(2)$ & $23(2)$ & $4(2)$ & $6(2)$ & $-3(2)$ \\
\hline $\mathrm{N}(1)$ & 11 (1) & $10(1)$ & $13(1)$ & $-1(1)$ & $-1(1)$ & 1 (1) \\
\hline $\mathrm{N}(2)$ & $13(1)$ & $11(1)$ & $9(1)$ & $0(1)$ & $0(1)$ & $-1(1)$ \\
\hline$S(1)$ & $20(1)$ & $13(1)$ & $18(1)$ & $2(1)$ & $8(1)$ & $-1(1)$ \\
\hline$S(2)$ & $24(1)$ & $9(1)$ & $17(1)$ & $-1(1)$ & $5(1)$ & $3(1)$ \\
\hline$S(3)$ & 29 (1) & $16(1)$ & $14(1)$ & $0(1)$ & $9(1)$ & $6(1)$ \\
\hline$S(4)$ & $15(1)$ & $18(1)$ & $12(1)$ & $-2(1)$ & $0(1)$ & $5(1)$ \\
\hline$S(5)$ & $10(1)$ & $14(1)$ & $13(1)$ & $3(1)$ & $-1(1)$ & $0(1)$ \\
\hline$S(6)$ & $13(1)$ & $19(1)$ & $14(1)$ & $4(1)$ & $3(1)$ & $2(1)$ \\
\hline $\mathrm{Cu}(1)$ & $9(1)$ & $9(1)$ & $10(1)$ & $-1(1)$ & $-1(1)$ & $2(1)$ \\
\hline
\end{tabular}

Table S10. Hydrogen coordinates $\left(\times 10^{4}\right)$ and isotropic displacement parameters $\left(\AA^{2} \times 10^{3}\right)$ for 3.

\begin{tabular}{|c|c|c|c|c|}
\hline & $x$ & $y$ & z & $\mathrm{U}(\mathrm{eq})$ \\
\hline $\mathrm{H}(2)$ & 1775 & 4404 & 7851 & 22 \\
\hline $\mathrm{H}(3)$ & 2930 & 3704 & 8041 & 21 \\
\hline $\mathrm{H}(7)$ & 6583 & 3327 & 9982 & 18 \\
\hline $\mathrm{H}(8)$ & 7918 & 3797 & 10985 & 17 \\
\hline $\mathrm{H}(12)$ & 4593 & 3060 & 10030 & 16 \\
\hline $\mathrm{H}(16)$ & 4842 & 3454 & 7764 & 19 \\
\hline $\mathrm{H}(17 \mathrm{~A})$ & 5086 & 2496 & 11074 & 41 \\
\hline $\mathrm{H}(17 \mathrm{~B})$ & 4406 & 2079 & 11292 & 41 \\
\hline $\mathrm{H}(17 \mathrm{C})$ & 3889 & 2546 & 10773 & 41 \\
\hline $\mathrm{H}(18 \mathrm{~A})$ & 3009 & 1703 & 8132 & 45 \\
\hline $\mathrm{H}(18 \mathrm{~B})$ & 3257 & 1308 & 7522 & 45 \\
\hline $\mathrm{H}(18 \mathrm{C})$ & 3121 & 1865 & 7244 & 45 \\
\hline $\mathrm{H}(19 \mathrm{~A})$ & 4456 & 3280 & 6352 & 50 \\
\hline $\mathrm{H}(19 \mathrm{~B})$ & 5154 & 3004 & 5890 & 50 \\
\hline
\end{tabular}




\begin{tabular}{|c|c|c|c|c|}
\hline $\mathrm{H}(19 \mathrm{C})$ & 5643 & 3253 & 6783 & 50 \\
\hline $\mathrm{H}(21)$ & 8138 & 4767 & 12853 & 17 \\
\hline $\mathrm{H}(25)$ & 9090 & 4530 & 10815 & 17 \\
\hline $\mathrm{H}(26 \mathrm{~A})$ & 8381 & 4894 & 14250 & 36 \\
\hline $\mathrm{H}(26 \mathrm{~B})$ & 8700 & 4507 & 14995 & 36 \\
\hline $\mathrm{H}(26 \mathrm{C})$ & 8185 & 4328 & 14056 & 36 \\
\hline $\mathrm{H}(27 \mathrm{~A})$ & 12409 & 4751 & 13015 & 36 \\
\hline $\mathrm{H}(27 \mathrm{~B})$ & 12968 & 4596 & 13960 & 36 \\
\hline $\mathrm{H}(27 \mathrm{C})$ & 12019 & 4950 & 13763 & 36 \\
\hline $\mathrm{H}(28 \mathrm{~A})$ & 10065 & 4039 & 10229 & 34 \\
\hline $\mathrm{H}(28 \mathrm{~B})$ & 11159 & 4161 & 10159 & 34 \\
\hline $\mathrm{H}(28 \mathrm{C})$ & 10437 & 4590 & 10274 & 34 \\
\hline $\mathrm{H}(30)$ & 6160 & 5838 & 9035 & 29 \\
\hline $\mathrm{H}(31)$ & 6914 & 5080 & 9043 & 30 \\
\hline $\mathrm{H}(32)$ & 6101 & 4481 & 8094 & 36 \\
\hline $\mathrm{H}(33)$ & 4534 & 4641 & 7136 & 33 \\
\hline $\mathrm{H}(34)$ & 3779 & 5399 & 7127 & 33 \\
\hline $\mathrm{H}(30 \mathrm{OB})$ & 6464 & 5396 & 8962 & 39 \\
\hline $\mathrm{H}(31 \mathrm{~B})$ & 6179 & 4639 & 8303 & 30 \\
\hline $\mathrm{H}(32 \mathrm{~B})$ & 4702 & 4500 & 7219 & 40 \\
\hline $\mathrm{H}(33 \mathrm{~B})$ & 3509 & 5117 & 6795 & 33 \\
\hline $\mathrm{H}(34 \mathrm{~B})$ & 3794 & 5874 & 7454 & 51 \\
\hline $\mathrm{H}(36)$ & 7595 & 1795 & 4446 & 24 \\
\hline $\mathrm{H}(37)$ & 7570 & 2142 & 3158 & 28 \\
\hline $\mathrm{H}(38)$ & 6351 & 2714 & 2530 & 31 \\
\hline $\mathrm{H}(39)$ & 5164 & 2949 & 3172 & 40 \\
\hline $\mathrm{H}(40)$ & 5187 & 2621 & 4471 & 36 \\
\hline $\mathrm{H}(41)$ & 5953 & 3780 & 4105 & 63 \\
\hline $\mathrm{H}(42)$ & 4964 & 4306 & 4594 & 82 \\
\hline $\mathrm{H}(43)$ & 5470 & 4556 & 5964 & 92 \\
\hline $\mathrm{H}(44)$ & 6905 & 4273 & 6860 & 98 \\
\hline $\mathrm{H}(45)$ & 7923 & 3743 & 6413 & 97 \\
\hline $\mathrm{H}(46)$ & 7437 & 3492 & 5006 & 75 \\
\hline $\mathrm{H}(47)$ & 5773 & 8137 & 6412 & 38 \\
\hline $\mathrm{H}(48)$ & 7016 & 8418 & 5860 & 36 \\
\hline $\mathrm{H}(49)$ & 7366 & 9248 & 5883 & 35 \\
\hline $\mathrm{H}(50)$ & 6483 & 9787 & 6480 & 38 \\
\hline $\mathrm{H}(51)$ & 5254 & 9501 & 7042 & 42 \\
\hline $\mathrm{H}(52)$ & 4883 & 8675 & 6991 & 41 \\
\hline
\end{tabular}

